\title{
The sensitivity of the EI Niño-Southern Oscillation to volcanic aerosol spatial distribution in the MPI Grand Ensemble
}

\author{
Benjamin Ward $^{1, \mathrm{a}}$, Francesco S. R. Pausata ${ }^{1}$, and Nicola Maher ${ }^{2,3,4}$ \\ ${ }^{1}$ Department of Earth and Atmospheric Sciences, University of Quebec in Montreal, Montreal, Canada \\ ${ }^{2}$ Max Planck Institute for Meteorology, Hamburg, Germany \\ ${ }^{3}$ Cooperative Institute for Research in Environmental Sciences (CIRES), University of Colorado at Boulder, \\ Boulder, CO, USA \\ ${ }^{4}$ Department of Atmospheric and Oceanic Sciences (ATOC), University of Colorado at Boulder, \\ Boulder, CO, USA \\ ${ }^{a}$ now at: Department of Atmospheric and Oceanic Sciences, McGill University, Montreal, Canada \\ Correspondence: Benjamin Ward (benjamin.ward@mcgill.mail.ca) and Francesco S. R. Pausata \\ (pausata.francesco@uqam.ca)
}

Received: 7 August 2020 - Discussion started: 19 August 2020

Revised: 30 July 2021 - Accepted: 5 August 2021 - Published: 17 September 2021

\begin{abstract}
Using the Max Planck Institute Grand Ensemble (MPI-GE) with 200 members for the historical simulation (1850-2005), we investigate the impact of the spatial distribution of volcanic aerosols on the El Niño-Southern Oscillation (ENSO) response. In particular, we select three eruptions (El Chichón, Agung and Pinatubo) in which the aerosol is respectively confined to the Northern Hemisphere, the Southern Hemisphere or equally distributed across the Equator. Our results show that relative ENSO anomalies start at the end of the year of the eruption and peak in the following one. We especially found that when the aerosol is located in the Northern Hemisphere or is symmetrically distributed, relative El Niño-like anomalies develop, while aerosol distribution confined to the Southern Hemisphere leads to a relative La Niña-like anomaly. Our results point to the volcanically induced displacement of the Intertropical Convergence Zone (ITCZ) as a key mechanism that drives the ENSO response, while suggesting that the other mechanisms (the ocean dynamical thermostat and the cooling of tropical northern Africa or the Maritime Continent) commonly invoked to explain the post-eruption ENSO response may be less important in our model.
\end{abstract}

\section{Introduction}

Aerosol particles from volcanic eruptions are one of the most important non-anthropogenic radiative forcings that have influenced the climate system in the past centuries (Robock, 2000). Oxidized sulfur gases (mainly in form of $\mathrm{SO}_{2}$ ) injected into the stratosphere by large Plinian eruptions form sulfate aerosols $\left(\mathrm{H}_{2} \mathrm{SO}_{4}\right)$ (Pinto et al., 1989; Pollack et al., 1976) that have a time residence of 1-3 years (Barnes and Hofmann, 1997; Robock and Liu, 1994). These particles both scatter and absorb incoming solar radiation as well as part of the outgoing longwave radiation (Stenchikov et al., 1998;
Timmreck, 2012). For intense and sulfur-rich volcanic eruptions, the net effect is a general cooling of the surface and a warming in the stratosphere where the aerosols tend to reside longer (Harshvardhan, 1979; Rampino and Self, 1984). The maximum global cooling seen in modelling studies is generally reached within 6-8 months following the eruption peak in optical depth before returning to normal values after about 3 to 4 years (Thompson et al., 2009). These rapid modifications in temperature may induce dynamical changes in the atmosphere and in the ocean, including a strengthening of the polar vortex (e.g. Christiansen, 2008; Driscoll et al., 2012; Kodera, 1994; Stenchikov et al., 2006), a weak- 
ening in the African and Indian Monsoon (e.g. Iles et al., 2013; Man et al., 2014; Paik et al., 2020; Trenberth and Dai, 2007; Zambri and Robock, 2016), and forced changes in the El Niño-Southern Oscillation (ENSO) (e.g. Emile-Geay et al., 2008; McGregor and Timmermann, 2011; Pausata et al., 2015a, b; Wang et al., 2018)

Paleoclimate archives and observations from the past centuries suggested that large tropical eruptions are usually followed by a warm sea surface temperature (SST) anomaly in the Pacific (e.g. Adams et al., 2003; D'Arrigo et al., 2005; Li et al., 2013; McGregor et al., 2010; Wilson et al., 2010) even if there are still uncertainties about the significance of theses results (Dee et al., 2020). In addition, El Niño events followed in the first or the second winter after the five largest eruptions of the last 150 years (Krakatau in August 1883, Santa Maria in October 1902, Agung in February 1963, El Chichón in March 1982 and Pinatubo in June 1991). However, the Santa Maria, El Chichón and Pinatubo eruptions occurred after an El Niño event was already developing, making it difficult to determine a causal link between ENSO and these eruptions (e.g. Self et al., 1997; Nicholls, 1988).

Moreover, modelling studies initially found divergent responses for the ENSO changes after large tropical eruptions (e.g. Ding et al., 2014; McGregor and Timmermann, 2011; Stenchikov et al., 2006; Zanchettin et al., 2012). However, the majority of the studies have pointed to an El Niño-like response following volcanic eruption (for a review of these studies, see McGregor et al., 2020). In particular, the use of relative sea surface temperature (RSST) or sea surface height (SSH) instead of SST have helped to disentangle the ENSO response from volcanically induced cooling in the Pacific and to highlight the dynamical ENSO response (Khodri et al., 2017; Maher et al., 2015). In this study, the terms El Niño-like and La Niña-like conditions are used to describe an anomalous warming or cooling of the equatorial Pacific relative to a climatology, and the term relative is used to describe deviations from the tropical average $\left(20^{\circ} \mathrm{N}-20^{\circ} \mathrm{S}\right)$.

Although a consensus is emerging, different aerosol spatial distributions may give rise to different ENSO responses. Stevenson et al. (2016) investigated the impact of Northern Hemisphere ( $\mathrm{NH})$, Southern Hemisphere ( $\mathrm{SH}$ ) and tropical volcanic eruptions using the Community Earth System Model Last Millennium Ensemble (CESM-LME). They concluded that while $\mathrm{NH}$ and tropical eruptions tend to favour El Niño-like conditions, SH eruptions enhance the probability of La Niña-like events within 1 year following the eruptions. Conversely, Liu et al. (2018), through a millennium simulation performed with CESM 1.0, and Zuo et al. (2018), using the CESM-LME, both concluded that SH, NH and tropical eruptions all resulted in El Niño-like conditions in the second year after the eruption.

The mechanisms that trigger a change in the ENSO state following volcanic eruptions are still debated. The centre of the argument is explaining how a volcanic eruption weakens or amplifies the trade winds (i.e. constant surface eastward winds within the tropics). One of the most frequently used hypotheses is the "ocean dynamical thermostat" mechanism (ODT) (Clement et al., 1996), where a preferential cooling in the western Pacific relative to the eastern Pacific takes place. Such a differential cooling weakens the zonal SST gradient along the equatorial Pacific, which causes a relaxation of the trade winds, leading to a temporary weakening of the ocean upwelling in the eastern Pacific. This process is then amplified by the Bjerknes feedback, yielding an El Niño (Bjerknes, 1969). A related mechanism for the preferential El Niño anomalies following volcanic eruptions is based on the recharge-discharge theory of ENSO, including changes in the wind stress curl during the eruption year as one of the triggering factors (McGregor and Timmermann, 2011; Stevenson et al. 2017). However, through a set of sensitivity experiments, Pausata et al. (2020) have questioned the existence of the ODT mechanism in coupled climate models following volcanic eruptions, pointing to the Intertropical Convergence Zone (ITCZ) displacement and extratropicalto-tropical teleconnections as key mechanisms in affecting post-eruption ENSO. The ITCZ shift mechanism was originally proposed for the ENSO response to high-latitude eruptions (Pausata et al., 2015b; 2016) and then suggested to also be at work for tropical asymmetric eruptions (Colose et al., 2016; Stevenson et al., 2016). Trade winds converge towards the ITCZ where their intensity weakens as the air circulates in an upward direction, creating the so-called doldrums (areas of windless waters). Consequently, a shift of the ITCZ affects the position of the doldrums and the intensity of the trade winds over the Equator. In general, the ITCZ shifts away from the hemisphere that is cooled (Kang et al., 2008; Schneider et al., 2014). Consequently, for an eruption with aerosol concentrated in the NH, the ITCZ location moves equatorward, weakening the trade winds and leading to an El Niño-like anomaly via the Bjerknes feedback (Bjerknes, 1969). In contrast, the ITCZ moves northward following a larger SH cooling compared to $\mathrm{NH}$, strengthening the trade winds and triggering La Niña-like anomalies, as seen in Colose et al. (2016) and Stevenson et al. (2016). Khodri et al. (2017) suggested that the cooling of tropical Africa following volcanic eruptions may increase the likelihood of an El Niño events through the weakening of the West African Monsoon and changes in the Walker circulation. More specifically, the authors suggest that the reduction of the tropical precipitation and tropospheric cooling favours anomalous atmospheric Rossby and Kelvin waves in autumn (SON), with a weakening of the trade winds over the western Pacific, leading to El Niño-like conditions in the year after the eruption. A similar mechanism has been suggested based on the cooling of the Maritime Continent or southeastern Asia instead of tropical Africa (Eddebbar et al., 2019; Ohba et al., 2013; Predybaylo et al., 2017). However, there is no consensus yet as to which of these proposed mechanisms is the main driver of the ENSO response after large volcanic eruptions. 
Modelling studies have investigated the impact of volcanic eruptions on ENSO using different approaches. Many studies have used a superposed epoch (SEA) or composite analysis, in which they used a window of a few years before the eruption to create a reference to compare with the posteruption period (e.g. Liu et al., 2018; Zuo et al., 2018). The significance of the response to volcanic eruptions is then assessed using a Monte Carlo method. However, this statistical methodology has some shortcomings as it is not able to fully remove the signal of internal variability: ENSO anomalies can still be seen in the reference period (see, for example, Fig. 4 in Liu et al., 2018). Some other studies use a small number of ensemble members with volcanic forcing and ensemble members without volcanic forcing starting from different initial conditions (e.g. McGregor and Timmermann, 2011; Predybaylo et al., 2017; Sun et al., 2019). However, when starting the two ensemble sets from different initial conditions, a large number of ensemble members (equivalent to at least 150 years reference period/climatology) is needed to isolate the internal variability of ENSO (Milinski et al., 2020; Wittenberg, 2009). A recent study by Predybaylo et al. (2020) additionally demonstrates the need for using large ensembles to investigate the ENSO response to volcanoes: by utilizing 54 100-member ensembles of idealized experiments, they found that the role of the initial ENSO state and the decomposition of the response into a deterministic and stochastic component is important, especially when highlighting the role of the ODT mechanism. Here, for the first time, we use a 200-member ensemble taken from the Max Planck Institute Grand Ensemble (MPI-GE) for the historical simulations (1850-2005) (Maher et al., 2019) to investigate the ENSO response to hemispherically symmetric and asymmetric volcanic eruptions. The large ensemble and the different aerosol distributions allow us to shed light on the mechanisms at play in altering the ENSO state after volcanic eruptions.

\section{Methodology and experimental design}

In this study we consider the three largest eruptions, in terms of quantity of aerosols injected in the stratosphere, of the last 100 years; Agung in Indonesia $\left(8^{\circ} \mathrm{S} 115^{\circ} \mathrm{E}\right)$ in February 1963; El Chichón in Mexico $\left(17^{\circ} \mathrm{N} 93^{\circ} \mathrm{W}\right)$ in March 1982; and Pinatubo in the Philippines $\left(15^{\circ} \mathrm{N} 120^{\circ} \mathrm{E}\right)$ in June 1991. Two eruptions have an asymmetrical aerosol distribution, so the aerosols are either confined to the $\mathrm{NH}(\mathrm{El}$ Chichón) or to the SH (Agung). The Pinatubo eruption has an approximately symmetrical distribution with the sulfate aerosols spread across both hemispheres. We also considered the eruption of Krakatau in Indonesia $\left(6^{\circ} \mathrm{S} 105^{\circ} \mathrm{E}\right)$ in 1883 , which is also modelled with an approximately symmetrical aerosol plume to further corroborate our results. For clarity, we only show the results for Pinatubo, which are qualitatively similar to Krakatau. The results of Krakatau are dis- played in Appendix A (Figs. A7, A8 and A9). The stratospheric aerosols used in this study are prescribed in the historical simulations of the model (MPI ESM) from the data set of Stenchikov et al. (1998) (Giorgetta et al., 2013). The data set consists of monthly averages of the radiative properties of the aerosols, such as the single-scattering albedo, and the aerosols extinction and the asymmetry factor, and they are based on satellite observations of Pinatubo's eruption (Schmidt et al., 2013).

We use 200 ensemble members of the historical simulations (1850-2005) performed using the Max Plank Institute for Meteorology Earth System Model 1.1 (MPI-ESM 1.1) (Giorgetta et al., 2013) as part of the Max Planck Institute Grand Ensemble (Maher et al., 2019). Such a large ensemble also allows us to analyse the ENSO response of individual eruptions instead of a composite of multiple eruptions as done in some previous studies that used a small number of ensembles (e.g. Maher et al., 2015; Stevenson et al., 2016; Zuo et al., 2018). All the ensemble members are initialized from different years of a long preindustrial control run (2000 years) after it has reached a quasi-stationarity state. The model horizontal resolution is roughly $1.8^{\circ}$ for the atmosphere and $1.5^{\circ}$ for the ocean with 16 vertical levels for both the atmosphere and the ocean. The MPI-ESM has been extensively used to investigate the impacts of volcanic eruptions on climate (e.g. Bittner et al., 2016; Illing et al., 2018; Timmreck et al., 2016). Specifically, our model is able to reproduce the global cooling of around $0.2^{\circ} \mathrm{C}$ following the three eruptions investigated in this study, as well as the high-latitude winter warming (locally up to $2^{\circ} \mathrm{C}$ ) after $\mathrm{El}$ Chichón and Pinatubo in the first winter after the eruption (see Fig. A18), in agreement with the estimates provided in the literature (e.g. Robock and Mao, 1995; Timmreck, 2012). Furthermore, while it has been argued that models need a sufficiently high top and that good vertical resolution is necessary to properly represent many of the surface climate effects of volcanic eruptions (e.g. Driscoll et al., 2012, SuarezGutierrez et al., 2021), we analysed 10 different global climate models and found that MPI-GE was the best model for representing both global and regional internal variability and forced response. Therefore, the limited number of vertical levels does not translate into a poor representation of the forced response associated with volcanic eruptions.

The anomalies calculated are the difference between the reference ( 3 years before the eruption and for the 200 ensemble members that we refer to as climatology) and periods after the eruption. A Student's $t$ test is used to estimate the significance of the mean changes before and after the eruptions at the $95 \%$ confidence level.

Large tropical eruptions induce a global cooling so that the El Niño response may be partly masked and the La Niña response amplified (Maher et al., 2015). Furthermore, some climate models overestimate the volcanically induced cooling (e.g. Anchukaitis et al., 2012; Stoffel et al., 2015). To better highlight the dynamical changes, we remove the trop- 
ical SST mean from the original SST, this is known as the relative sea surface temperature (RSST) (Vecchi and Soden, 2007). In this study, we use the RSST to isolate the intrinsic ENSO signal, but the analyses using the SST are available in Appendix A (Khodri et al., 2017).

\section{Results}

\subsection{ENSO response and its links to the ITCZ shift mechanism}

The volcanic eruptions analysed in the present study show three distinct aerosol plumes. While the aerosol distribution from the Pinatubo eruption is symmetrical around the Equator, the Agung and El Chichón eruptions created, to a large extent, a confined distribution in the $\mathrm{SH}$ and the $\mathrm{NH}$, respectively (Fig. 1). For Pinatubo and El Chichón the aerosol optical depth peaks in the winter that follows the eruptions. For Agung this maximum is reached in the winter of the second year after the eruption. The reasons why similar eruptions can lead to different aerosol distributions are still being investigated, but some causes are the location of the volcanoes, the season and the strength of the eruption (Stoffel et al., 2015; Toohey et al., 2011), the quasi-biennial oscillation, and local meteorology (e.g. Choi et al., 1998), which determine wind direction and the aerosols distribution across the Equator. Regarding the Pinatubo aerosol distribution, we note that the eruption was followed after a few months by the eruption of Mount Hudson (Chile) in the Southern Hemisphere. As the aerosol distribution for Pinatubo is based on satellite observations, the aerosol properties prescribed to the model also include Mount Hudson eruption.

Our simulations show a relative El Niño-like response to the El Chichón and Pinatubo eruptions and a relative $\mathrm{La}$ Niña-like response to the Agung eruption (Figs. 2 and 3). The relative ENSO anomalies develop at the beginning of the year after the eruption (Year 2) and then peak that boreal winter for El Chichón and Pinatubo or in the third boreal winter for Agung. The westerly anomalies in the trade winds are detected starting in the autumn of the eruption (Year 1). For all of the eruptions, the relative Niño 3.4 index peaks in the winter of the year after the eruption, reaching a maximum of approximately $+0.3^{\circ}$ for El Chichón and Pinatubo and a minimum of $-0.2^{\circ}$ for Agung (Fig. A3). The results using the SST (Figs. A11, A12 and A13) are qualitatively similar to the RSST (Figs. 2, 3, and A3), but the El Niñolike anomalies are less strong since they are partially masked by the global cooling induced by the stratospheric aerosols, which is in agreement with other studies (Khodri et al., 2017; Maher et al., 2015).

Furthermore, the temperature anomalies following the Agung eruption are not merely superficial but extend down to $200 \mathrm{~m}$ depth (Fig. A14). The warming below $100 \mathrm{~m}$ in the western Pacific and the cooling along the thermocline in the eastern side of the basin are typical of an ongoing La Niña: the pattern is indeed remarkably similar to a composite of La Niña events occurring in the reference periods before the three eruptions (Fig. A17). On the other hand, the temperature anomalies for the El Chichón and Pinatubo eruptions show opposite results to what is expected under El Niño-like conditions (Figs. A15 and A16). Moreover, the wind anomalies following Agung (see Figs. 2 and 3) are the opposite of El Chichón, hence leading to opposite upwelling conditions along the Equator, further corroborating that the ocean temperature anomalies are mostly dynamically driven through the Bjerknes feedback (Bjerknes, 1969). The different forcing caused by the three eruptions induces a different cooling of the surface temperature in the two hemispheres (Fig. 4). Although Pinatubo is the most intense eruption and has the largest global temperature decrease (Fig. A1), El Chichón shows the strongest hemispherical cooling (Fig. 4). The relative hemispherical cooling associated with Agung $(\mathrm{SH})$ is in absolute values comparable to Pinatubo even if Agung's quantity of aerosols injected in the stratosphere was twice as small (Bluth et al., 1992; Self and Rampino, 2012). Furthermore, while the aerosol distribution of the Pinatubo eruption is symmetric, the relative cooling is not and is concentrated in the $\mathrm{NH}$, which is likely due to uneven distribution of landmass between hemispheres (i.e. reduced heat capacity in the $\mathrm{NH})$. The maximum cooling for all three eruptions occurs in the second year, as does the temperature difference between the two hemispheres (Figs. 4 and A1).

Precipitation anomalies (Figs. 5 and 6) show the displacement of the Hadley cell associated with the differential cooling between the hemispheres, showing a northward shift of the ITCZ for the eruption of Agung and a southward shift for both El Chichón and Pinatubo for the 3 years following the eruptions. Additionally, Pinatubo's rainfall anomaly is the largest even though the difference in the cooling of each hemisphere is stronger for El Chichón. This indicates that the ITCZ response is sensitive to the magnitude and spatial distribution of the forcing. The on-going global warming could also amplify the rainfall anomaly following the volcanic eruptions through modulation in the ocean stratification and near-surface winds amplifying the response as suggested in a recent study (Fasullo et al., 2017) (Fig. A9). Moreover, the precipitation asymmetry index (PAi) (Colose et al., 2016) further highlights the ITCZ shift and weakening (Fig. 7). The expression for the PAi is given by

$\mathrm{PAi}=\frac{P_{20^{\circ} \mathrm{N}-10^{\circ} \mathrm{N}}-P_{10^{\circ} \mathrm{N}-\mathrm{Eq}}}{P_{20^{\circ} \mathrm{N}-\mathrm{Eq}}}$.

It represents the variation of the zonal precipitation around the average climatological mean of the ITCZ in our model, which is roughly $10^{\circ} \mathrm{N}$. In Fig. 7, the positive variation of the PAi after the Agung eruption corresponds to a northward shift of the ITCZ and the negative variations of the PAi after the Pinatubo and El Chichón eruptions corresponds to a southward shift of the ITCZ. 


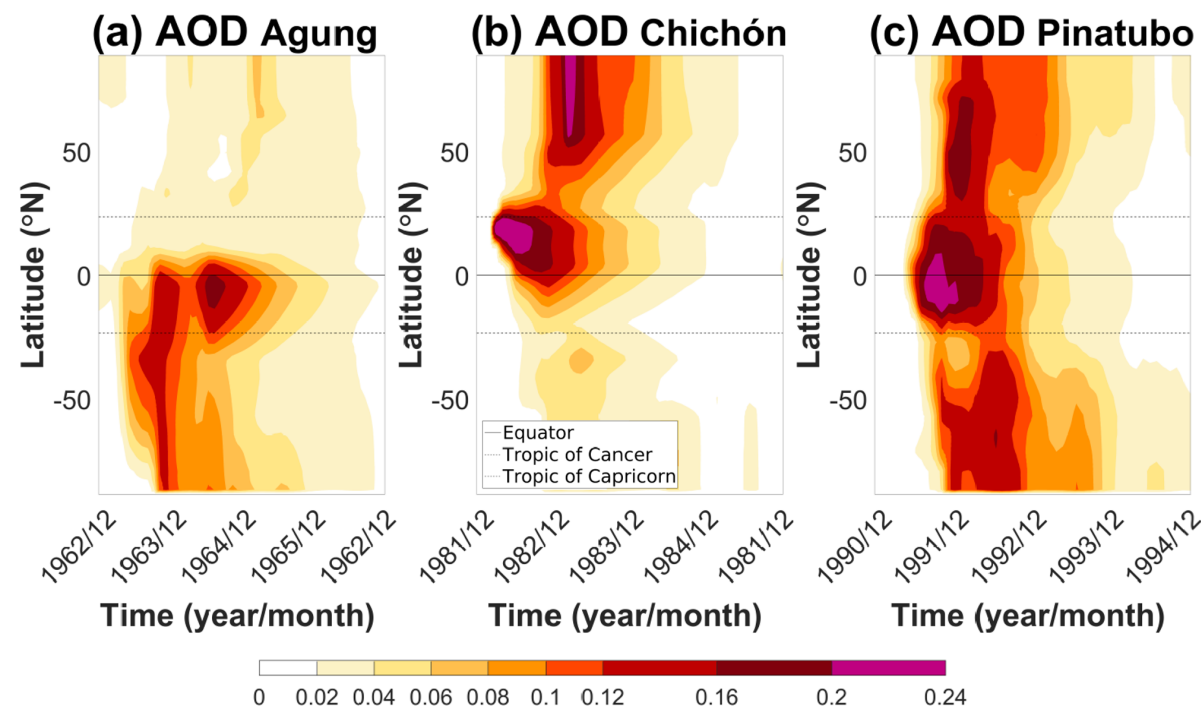

Figure 1. Evolution of the aerosol optical depth during 4 years for the three eruptions. The band of wavelength used is between approximately 462 and $625 \mathrm{~nm}$.

Agung
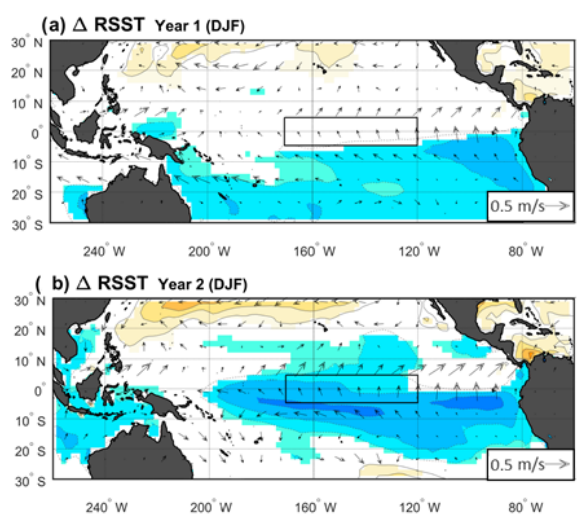

$240^{\circ} \mathrm{W}$

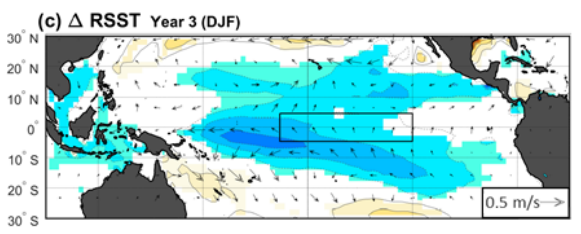

$240^{\circ} \mathrm{W} \quad 200^{\circ} \mathrm{W} \quad 160^{\circ} \mathrm{W} \quad 120^{\circ} \mathrm{W} \quad 80^{\circ} \mathrm{W}$
El Chichón

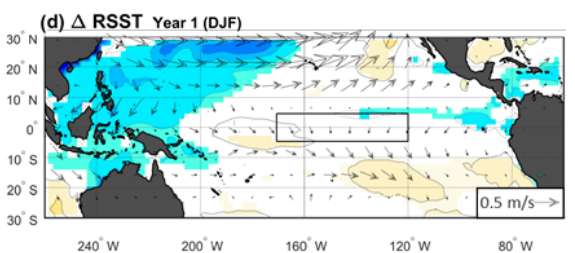

(e) $\triangle$ RSST Year 2 (DJF)

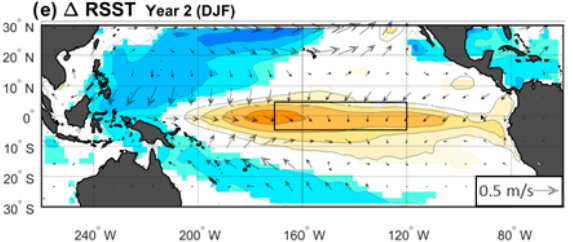

$\triangle$ RSST Year 3 (DJF)

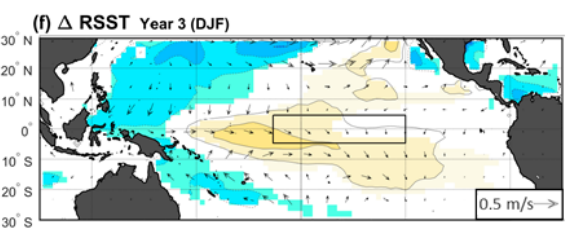

Pinatubo
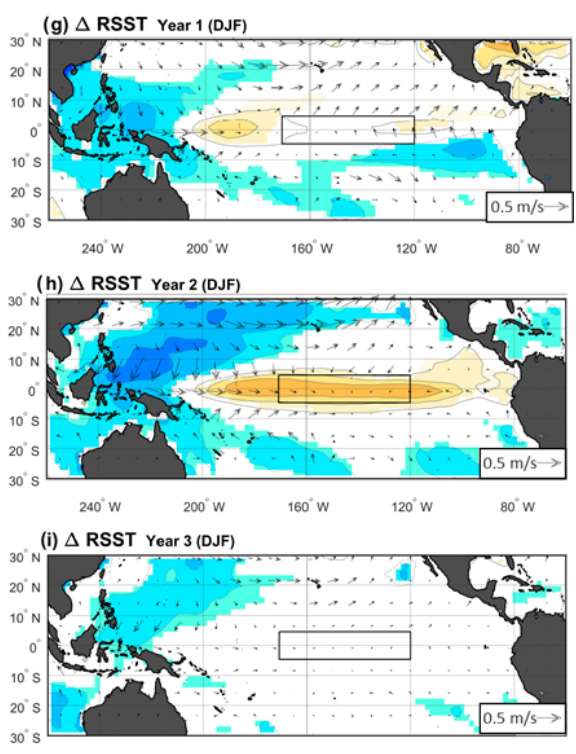

$240^{\circ} \mathrm{W} \quad 200^{\circ} \mathrm{W} \quad 160^{\circ} \mathrm{W} \quad 120^{\circ} \mathrm{W} \quad 80^{\circ} \mathrm{W}$

Figure 2. Ensemble mean of changes in relative sea surface temperature (RSST) (shadings) and $10 \mathrm{~m}$ winds (arrows) between the volcano case and the climatology for each of the following three winter seasons (DJF) after the Agung (a-c), El Chichón (d-f), and Pinatubo (g-i) eruptions. Only significant RSST changes are shaded with an approximate $95 \%$ confidence level using Student's $t$ test. Contours show the RSST anomalies following the colour bar scale (solid lines for positive anomalies and dashed lines for negative anomalies; the 0 line is omitted). The boxes indicate the Niño 3.4 area.

We find that the ITCZ displacement and associated rainfall anomalies peak in the second year after the eruption, when the differential cooling of the hemisphere is larger (Figs. 4, 5, 6 and 7). The ITCZ displacement is associated with a strengthening of the trade winds for the Agung eruption and a weakening for the El Chichón and Pinatubo eruptions as expected by the direction of the ITCZ movement in each case. These wind anomalies then affect the ENSO state: a change in the strength of the trade winds along the equatorial Pacific alters the ocean upwelling in the eastern side. This leads to a 


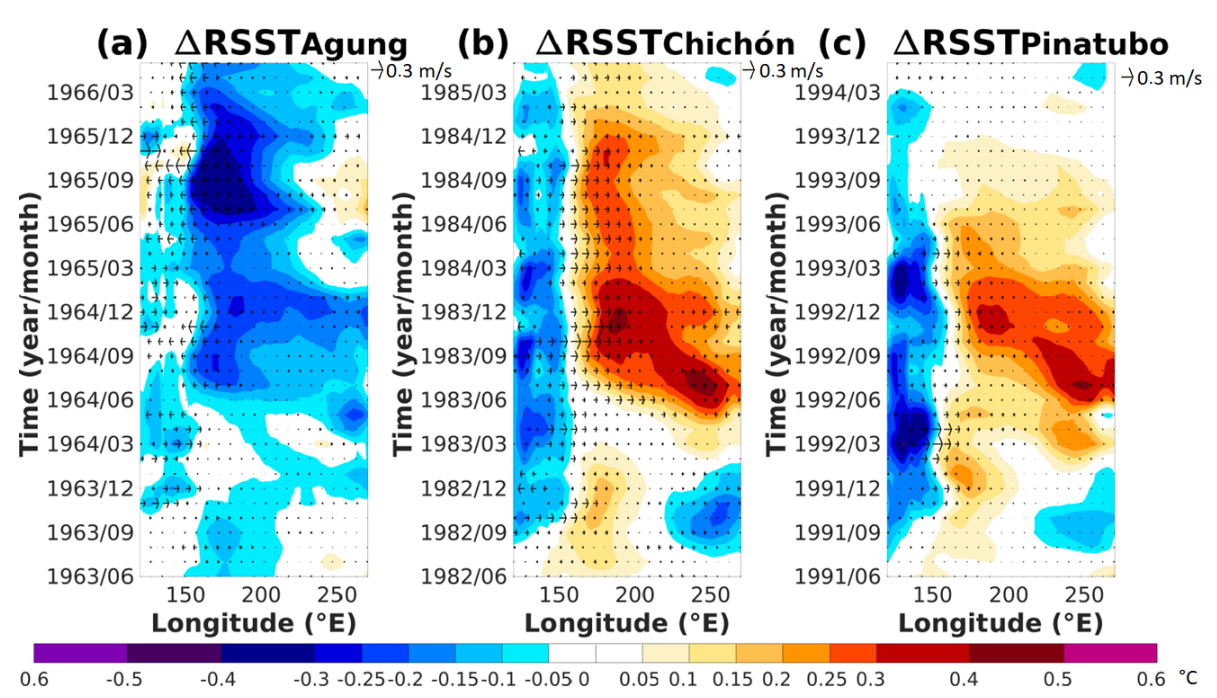

Figure 3. Hovmöller plot of the ensemble mean of the relative SST anomalies in the equatorial Pacific (averaged over -5 and $5^{\circ} \mathrm{N}$ ) and the change in the zonal component of the $10 \mathrm{~m}$ winds $(\mathrm{m} / \mathrm{s})$ for the 3 years following each eruption. The anomalies are calculated relative to the 3 years before each eruption.

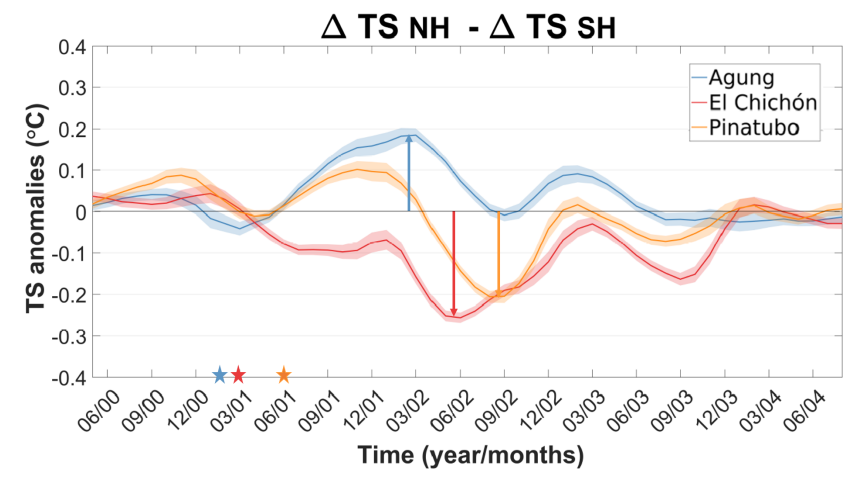

Figure 4. Evolution of the difference in the ensemble mean between the volcanically induced cooling of the SH and the $\mathrm{NH}$ after each eruption $\left(\Delta T_{\mathrm{NH}}-\Delta T_{\mathrm{SH}}\right)$. Shading represents twice the standard error of the ensemble mean (i.e. $\sim 95 \%$ confidence interval).

change in the east-west temperature contrast across the tropical Pacific, which is amplified by the Bjerknes feedback, thus altering the ENSO state. All of our results (the evolution of the relative Niño 3.4 index, the precipitation anomalies or the relative temperature anomalies) show an almost perfect symmetry between the symmetrical and $\mathrm{NH}$ distribution, versus the SH distribution (Figs. 2, 3, 4, 5, 6 and A2), which strongly suggests that the volcanically induced ITCZ displacement is the key mechanism to explain the ENSO response to the volcanic forcing in agreement with other studies (Colose et al., 2016; Pausata et al., 2016; Stevenson et al., 2016; Pausata et al., 2020).

\subsection{ENSO response and its link to other mechanisms}

The most commonly invoked mechanism that explains the ENSO response after large tropical volcanic eruptions is the ODT mechanism (Clement et al., 1996) and the preferential cooling of the warm pool relative to the eastern equatorial $\mathrm{Pa}$ cific, leading to an El Niño-like response (e.g. Emile-Geay et al., 2008; Mann et al., 2005). However, in our simulations, even if there is a volcanic aerosol over the equatorial $\mathrm{Pa}$ cific and a surface cooling for all the eruptions (Figs. 1, A3, A4 and A5), we see a negative phase of the relative ENSO and an anomalous easterly wind stress developing after the Agung eruption (Figs. 2 and 3). Should the ODT mechanism be dominant in our model, we would expect the opposite response of both the relative SST and wind stress. This suggests that the ODT is likely not the leading mechanism in our model, while not ruling out that it can still play a role under specific initial conditions (e.g. Predybaylo et al., 2020). Another mechanism often used to explain how the post-eruption El Niño-like response is related to the cooling of the Maritime Continent first proposed by Ohba et al. (2013) and also suggested in recent studies (e.g. Eddebbar et al., 2019): the smaller heat capacity of the land in comparison to the ocean cause a stronger land cooling that reduces the temperature gradient between the Maritime Continent and the western Pacific Ocean. Such temperature changes lead to a weakening of the trade winds and an eastward shift of the rainfall (El Niño pattern). Our results show a cooling of the Maritime Continent and a reduction of the convective activity in the three eruptions (Figs. A3, A4 and A5). Nevertheless, our model simulates the development of a relative La Niña-like conditions after the eruption of the Agung (Figs. 1 and 2), which is at odds with the cooling of the Maritime Continent 


\section{Agung}
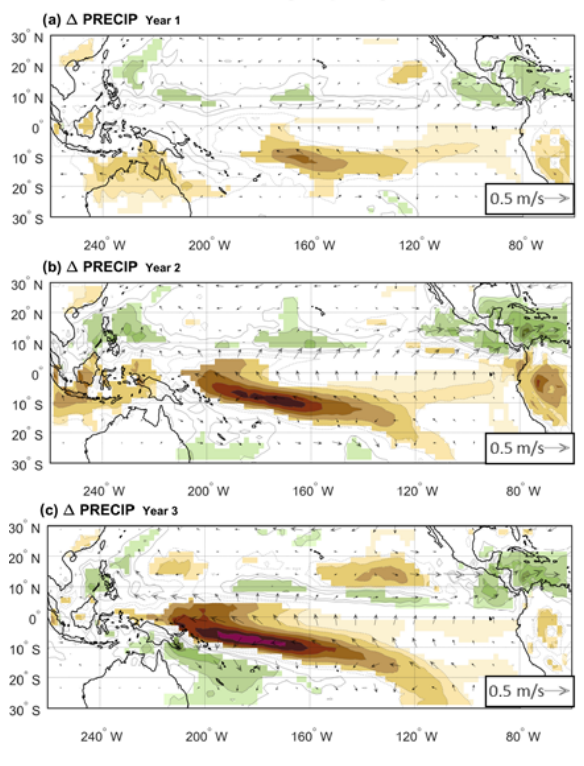

El Chichón
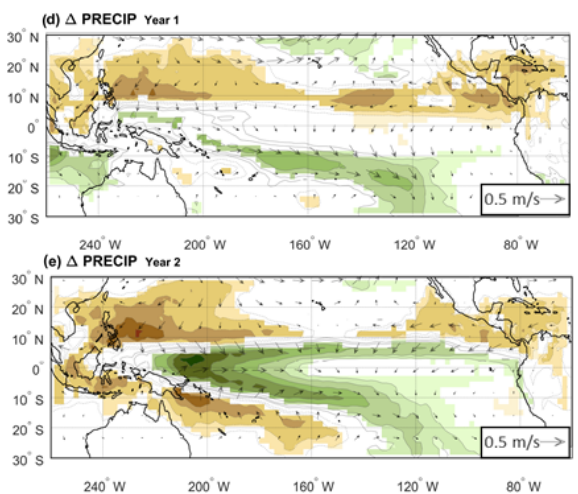

$240^{\circ} \mathrm{W}$

$30^{\circ} \mathrm{N} \triangle \mathrm{N}$ PRECIP Year

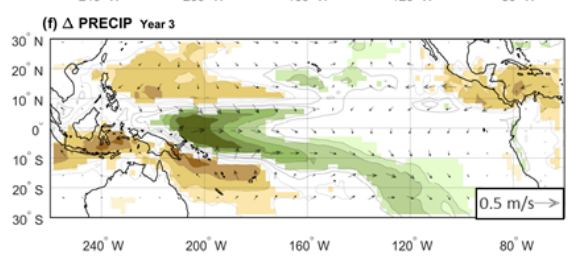

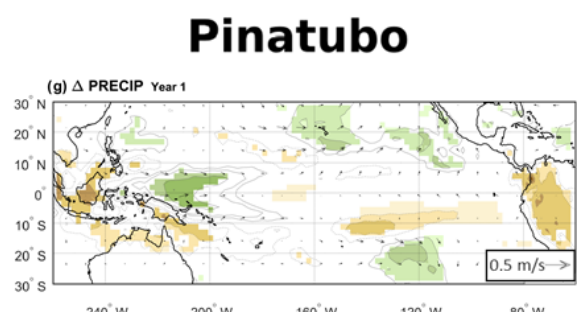

(h) $\triangle$ PRECIP Year 2
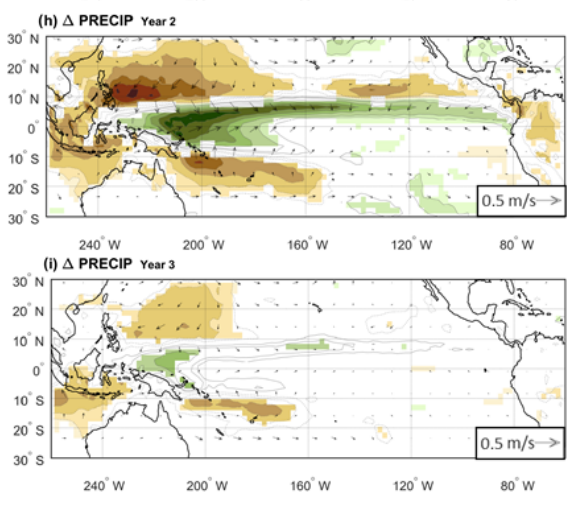

$\begin{array}{llllllllll}-1.4 & -1.2 & -1 & -0.8 & -0.6 & -0.4 & -0.2-0.10 & 0.10 .2 & 0.4 & 0.6\end{array}$

$\begin{array}{llll}0.8 & 1 & 1.2 & 1.4\end{array}(\mathrm{~mm} / \mathrm{days})$

Figure 5. Change in ensemble mean precipitation and $10 \mathrm{~m}$ winds (arrows) between the reference years and the volcano case for the three summer to winter seasons (June to February) following the Agung (a-c), El Chichón (d-f) and Pinatubo (g-i) eruptions. Contours show the precipitation anomaly following the colour bar scale (solid lines for positive anomalies and dashed lines for negative anomalies, the 0 line is omitted). Only precipitation changes that are significant at the $95 \%$ confidence level using Student's $t$ test are shaded.

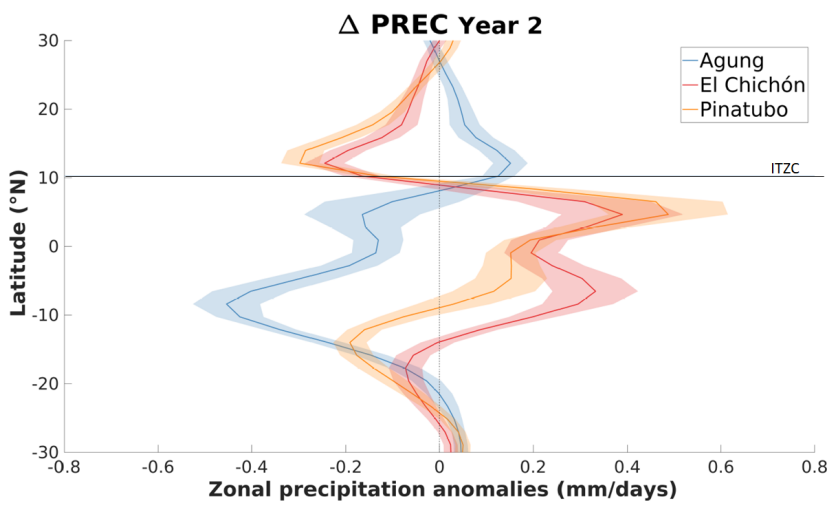

Figure 6. Ensemble mean of the zonal precipitation anomaly over the Pacific Ocean $\left(160^{\circ} \mathrm{E}-100^{\circ} \mathrm{W}\right)$ between the summer to winter seasons (June to February) of the second year after each eruption and the 3-year climatology. Shading represents twice the standard error of the ensemble mean (i.e. $\sim 95 \%$ confidence interval). The horizontal line highlights the ensemble-mean 3-year climatology position of the ITCZ (defined as the location of the zonal-average precipitation maximum).

mechanism, where relative El Niño-like conditions would be expected for all three eruptions.

Khodri et al. (2017) suggested that the cooling of tropical Africa, following volcanic eruptions, may increase the likelihood of an El Niño events through the weakening of

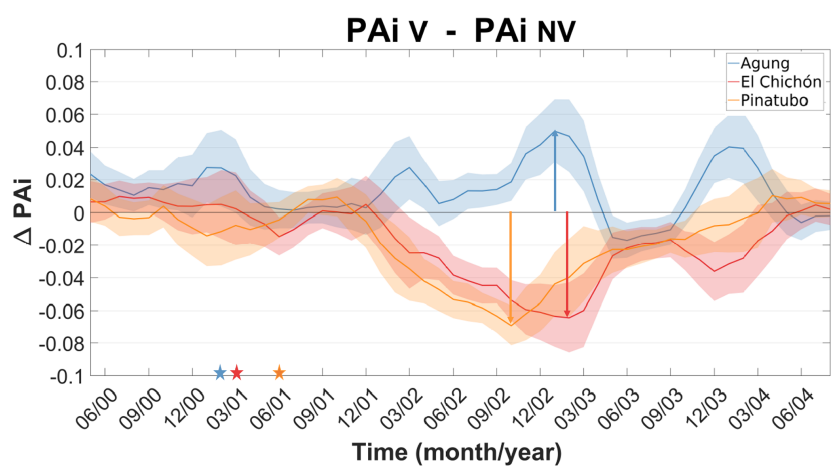

Figure 7. Evolution of the difference in the ensemble mean between the precipitation asymmetry index (PAi) after each eruption $\left(\mathrm{PAi}_{V}\right)$ and the climatology $\left(\mathrm{PAi}_{\mathrm{NV}}\right)$. Shading represents twice the standard error of the ensemble mean (i.e. $\sim 95 \%$ confidence interval). The three stars represents the moment of each eruption.

the West African Monsoon and changes in the Walker circulation. More specifically, the reduction of the tropical precipitation and tropospheric cooling favours anomalous atmospheric Rossby and Kelvin waves in autumn (SON), with a weakening of the trade winds over the western Pacific, leading to El Niño-like conditions in the year after the eruption. Our results show a mixed response over Africa, with Agung and Pinatubo both displaying a cooling (Figs. A3 and A5) but leading to different relative ENSO responses (Figs. 1 and 
2). Moreover, after the El Chichón eruption a warming of the tropical northern Africa takes place in the first year and an El Niño-like anomaly develops (Figs. 2, 3 and A4). Hence, in our model the volcanically induced cooling of tropical Africa and the atmospheric perturbations associated with the suppression of the African monsoon seem to not play a critical role in altering the ENSO state following volcanic eruptions.

Recently, Pausata et al. (2020) proposed an additional mechanism related to the extratropical-to-tropical teleconnections that tends to favour an El Niño-like response for both $\mathrm{NH}$ and $\mathrm{SH}$ eruptions, hence playing in synergy with (NH eruptions) or against (SH eruptions) the ITCZ shift mechanism. However, our qualitative analysis of the sea level pressure (SLP) anomalies does not match the changes expected by this mechanism (cf. Figs. A10 with 4a-d in Pausata et al., 2020). In this recent study, the volcanic aerosol alters the meridional temperature gradient of the atmosphere that eventually causes a poleward shift of the Pacific jet stream and a strong cyclonic surface pressure anomaly over the midlatitudes to the subtropical Pacific basin in both $\mathrm{NH}$ and $\mathrm{SH}$ eruptions in the first summer following the eruptions. In our simulation, the response is opposite for the Agung and El Chichón or Pinatubo eruptions, suggesting more that the simulated extratropical anomalies are induced by the relative ENSO changes due to the eruption rather than affecting ENSO (Fig. A10). The reason for the disagreement could lie in the fact that the El Niño and La Niña-like responses following the volcanic eruptions peak in the first winter in the Pausata et al. (2020) modelling study, while in our model they peak in the second winter (Figs. 2 and 3). The extratropical-to-tropical teleconnection could make the El Niño development following NH and symmetric eruptions occur faster than in our case, where such a teleconnection appears to not be present. Ad hoc sensitivity experiments are necessary to rule out the above-mentioned mechanisms in our model.

\section{Discussion and conclusions}

Our study used the largest ensemble simulation (200 ensembles) currently available of the historical period performed with the MPI-ESM model to better understand the impact of the volcanic eruptions on ENSO. Our results strongly point to the volcanically induced ITCZ displacement as the primary driver of the ENSO response following volcanic eruptions in this model. In our simulations, the ENSO response after the eruptions critically depends on the distribution of the aerosol plume. When the volcanic aerosol distribution is confined to the $\mathrm{NH}$ or its distribution is symmetrical across the hemispheres, the ENSO state tends towards a positive phase (relative El-Niño-like conditions; Fig. 2d-i), while when the aerosols are confined to the SH the ENSO state is pushed towards a negative phase (relative La Niña-like conditions; Figs. 2a-c). The displacement of the ITCZ following the eruptions is caused by the asymmetric cooling of the hemisphere that pushes the ITCZ towards the hemisphere that is less cooled (Kang et al., 2008; Schneider et al., 2014). Both the eruptions with aerosol confined to the $\mathrm{NH}$ and symmetrically distributed across the hemispheres preferentially cool the $\mathrm{NH}$, consequently shifting the ITCZ southwards, weakening the trade winds over the equatorial Pacific and triggering an El Niño like response through the Bjerknes feedback (Bjerknes, 1969). The eruption with the aerosol plume confined to the SH instead exclusively cools the $\mathrm{SH}$, pushing the ITCZ northward and strengthening the trade winds, leading to La Niña-like response (Figs. 5, 6 and 7).

The ITCZ mechanism we see at play in our model is supported by other recent studies performed with different climate models (Pausata et al., 2015b, 2020; Stevenson et al., 2016; Colose et al., 2016). Pausata et al. (2020), through a set of sensitivity experiments in which the volcanic aerosol forcing is confined to either the $\mathrm{NH}$ or the $\mathrm{SH}$, show the key role of the ITCZ displacement in driving the ENSO response. They also highlighted the presence of another mechanism related to the extratropical-to-tropical teleconnections that no matter the type of eruption (NH or $\mathrm{SH}$ ) tends to favour an El-Niño like response. Hence, it plays in synergy with (NH eruptions) or against (SH eruptions) the ITCZ shift mechanism. However, the simulated SLP changes in the extratropics in our model seem to be in response to the volcanically induced ENSO changes rather than affecting the ENSO response (cf. Figs. A10 with 4a-d in Pausata et al., 2020).

Our work also pointed out that the ODT (Clement et al., 1996) and the cooling of the Maritime Continent (Ohba et al., 2013) and tropical Africa (Khodri et al., 2017) are likely not the dominant drivers of the ENSO response in the MPI-GE model. Discrepancies between these previous studies and our results may occur for three reasons. First, different models may present different mechanisms. The fact that the abovementioned mechanisms are not dominant is also in qualitative agreement with the modelling experiments in Pausata et al. (2020), who use the Norwegian Earth System Model (NorESM). Another study using all the ensemble members (14) of a large ensemble (CESM-LME) is also in overall agreement with our results (Stevenson et al., 2016), finding a La Niña-like response to SH eruption and an El Niño-like response to $\mathrm{NH}$ and tropical eruption. However, other studies using either a subset (five members) of the CESM total ensemble (Zuo et al., 2018) or an early version of CESM with only one ensemble (Liu et al., 2018) display El Niñolike anomalies for all type of eruptions, which brings us to the following point. Second, most previous studies are based on a small number of ensemble members (e.g. five members for three eruptions for the SH plume in Zuo et al., 2018) or they heavily rely on statistical tools using a small sample of events (e.g. SEA in Liu et al., 2018). Consequently, those results may be biased by the use of a restrained number of ensemble members. Here, our study points out the importance of a large number of ensemble members when investi- 
gating the ENSO response to volcanic eruptions. Third, the role of the initial ENSO state is important for determining the ENSO response (Pausata et al., 2016; Predybaylo et al., 2017) and consequently it influences the role of the ODT and the other above-mentioned mechanisms. Our study only considers the total climate response to volcanic forcing; however, in a recent study, Predybaylo et al. (2020) separated the ENSO response to volcanic eruptions into a deterministic and stochastic response. They have shown that the deterministic response is dominant for spring and summer eruptions, while stochastic response plays a major role for eruptions occurring in winter. However, our experimental design does not allow the separation of the total climate response into the deterministic and stochastic component, with further future experiments needed in which the volcano and the reference non-volcano ensemble members start from the same initial conditions.

Finally, our results are consistent with the predominance of post-eruption El Niño events (Adams et al., 2003; McGregor et al., 2020) and can provide an explanation as to why the majority of both observations and reconstructions are displaying El Niño events instead of La Niña events. However, the ENSO responses discussed in this study are only tendential (El Niño-like or La Niña-like response); i.e. intrinsic variability evolving toward a La Niña at the time of the eruption does not necessarily lead to a post-eruption El Niño event even for a NH or symmetrical eruption but instead to a dampening of the ongoing La Niña. Furthermore, our model suggests the peak of ENSO anomalies to be in the second or third winter after the eruption, similar to most modelling studies (Khodri et al., 2017; Lim et al., 2016; McGregor and Timmermann, 2011; Ohba et al., 2013; Stevenson et al., 2017). This is at odds with the reconstructions and observations that see a peak in ENSO anomalies in the first winter following the eruption (McGregor et al., 2010, 2020) and possibly extending to the second year (Adams et al., 2003). The delayed ENSO response in our model simulations relative to reconstructions and observations may be related to the apparent lack of extratropical-to-tropical teleconnections (Pausata et al., 2020) that could favour El Niño-like response already in the first winter following the eruption or other biases within the climate models (e.g. double ITCZ).
In conclusion, our results provide further insights into the mechanism driving the ENSO response to volcanic eruptions, highlighting the role of the ITCZ shift in particular. However, further coordinated efforts with specific sensitivity studies are necessary to delve into the other proposed mechanisms and to unravel the difference between modelling studies and reconstructions with regards to the peak of the ENSO response. Given that ENSO is the major leading mode of tropical climate variability, which has worldwide impacts, these types of studies are also necessary to help improve seasonal forecasts following large volcanic eruptions. 


\section{Appendix A}

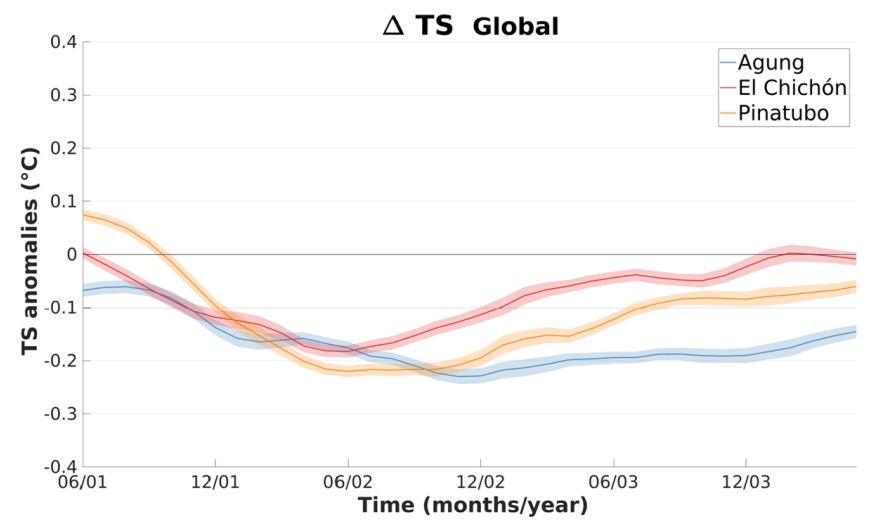

Figure A1. Evolution of the ensemble mean of the global cooling in the three eruption cases for 3 years, starting at the first summer after the eruption. The 3-year climatology is subtracted to calculate the anomalies. Shading represents twice the standard error of the ensemble mean (i.e. $\sim 95 \%$ confidence interval).

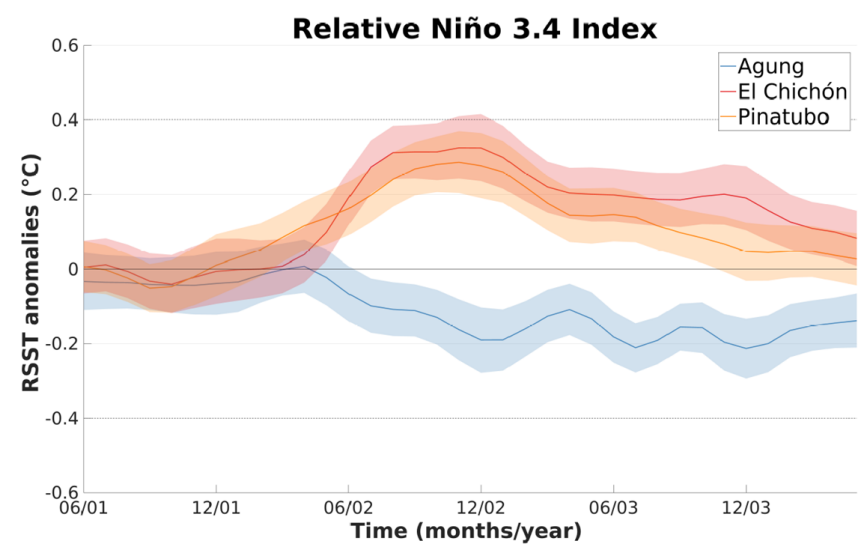

Figure A2. Ensemble mean changes in the relative Niño 3.4 index after each eruption. The 3-year climatology is subtracted to calculate the anomalies. Shading represent twice the standard error of the mean using an approximate $95 \%$ confidence interval. 


\section{Agung}

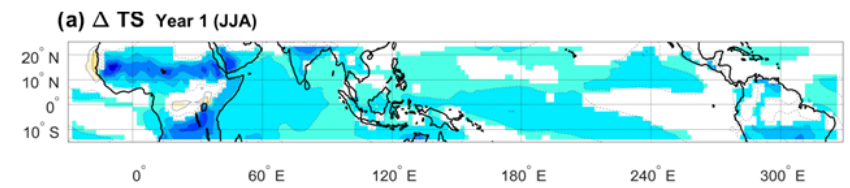

(e) $\triangle$ PRECIP Year 1 (JJA)

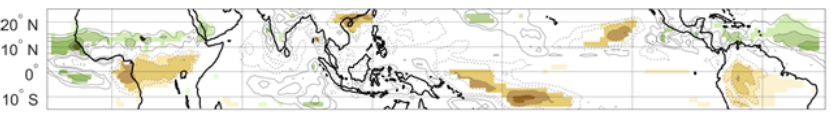

(b) $\Delta$ TS Year 1 (SON)

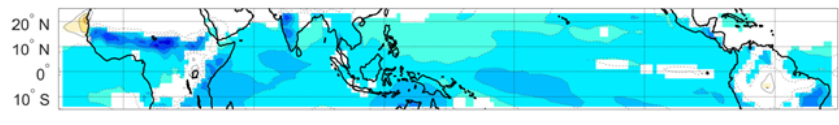

(f) $\triangle$ PRECIP Year 1 (SON)
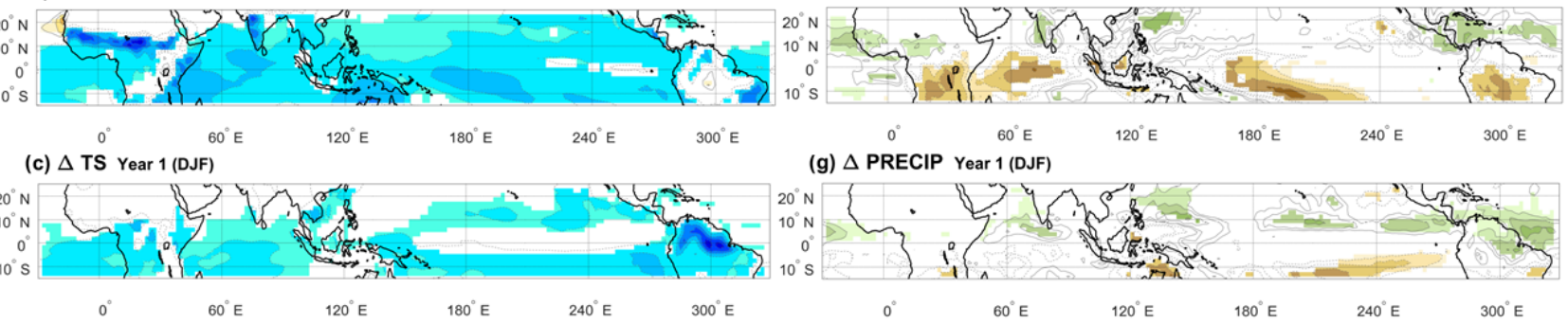

(g) $\triangle$ PRECIP Year 1 (DJF)

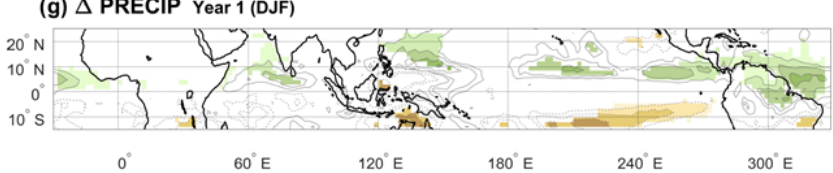

(d) $\Delta$ TS Year 1 (MAM)

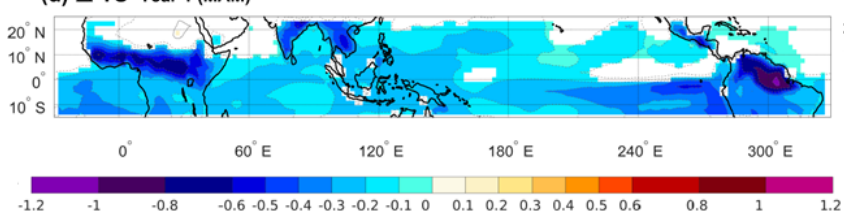

(h) $\triangle$ PRECIP Year 1 (MAM)

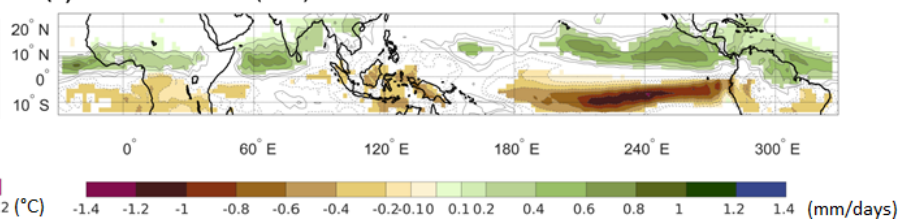

Figure A3. Ensemble mean of changes in surface temperature $(\mathbf{a}, \mathbf{b}, \mathbf{c}, \mathbf{d})$ and precipitation $(\mathbf{e}, \mathbf{f}, \mathbf{g}, \mathbf{h})$ between the climatology and the volcano case for each season of the year after the Agung eruption. Only significant anomalies are shown with an approximate $95 \%$ confidence level using Student's $t$ test. Contours show temperature and precipitation anomalies following the colour bar scale (solid line for positive anomalies and dashed line for negative anomalies).

(a) $\Delta$ TS Year 1 (JJA)

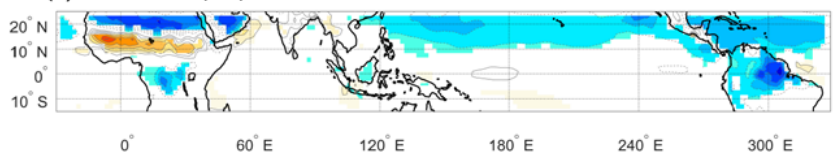

(b) $\Delta$ TS Year 1 (SON)

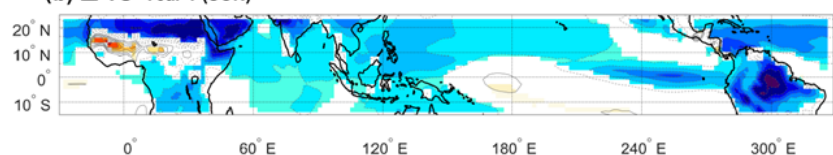

(c) $\Delta$ TS Year 1 (DJF)

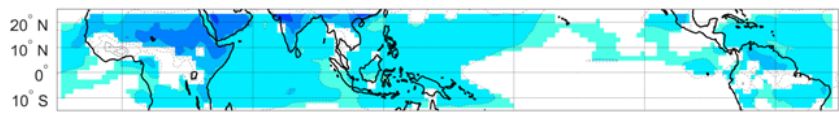

(d) $\triangle \mathrm{TS}$ Year 1 (MAM)

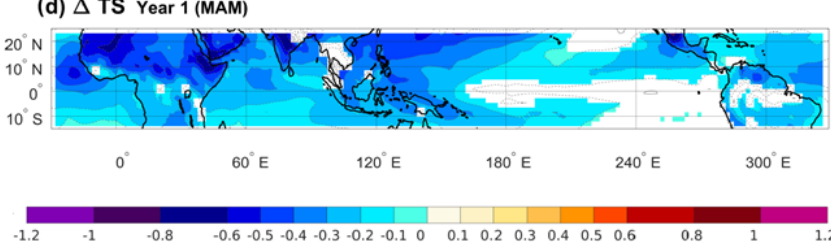

\section{El Chichón}

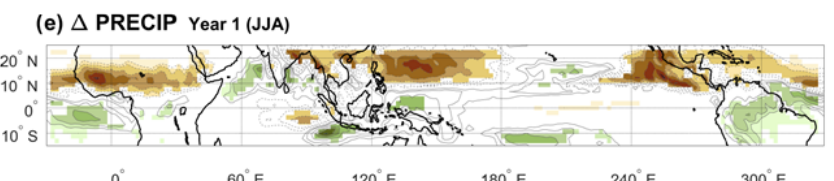

(f) $\triangle$ PRECIP Year 1 (SON)
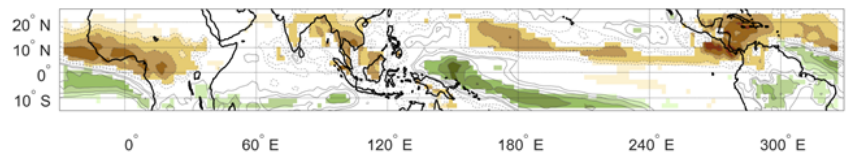

(g) $\triangle$ PRECIP Year 1 (DJF)

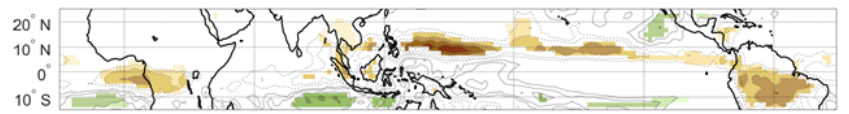

$\begin{array}{cc}0^{\circ} & 60^{\circ} \mathrm{E} \\ \text { (h) } \triangle \text { PRECIP } & \text { Year } 1 \text { (MAM) }\end{array}$

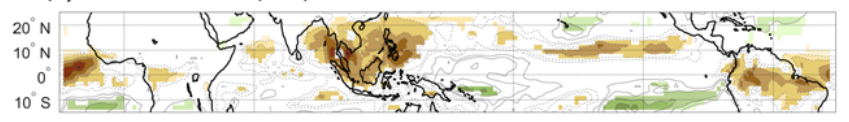

$2\left({ }^{\circ} \mathrm{C}\right)$

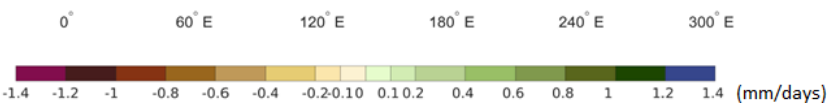

Figure A4. Ensemble mean of changes in surface temperature $(\mathbf{a}, \mathbf{b}, \mathbf{c}, \mathbf{d})$ and precipitation $(\mathbf{e}, \mathbf{f}, \mathbf{g}, \mathbf{h})$ between the climatology and the volcano case for each season of the year after the El Chichón eruption. Only significant anomalies are shown with an approximate $95 \%$ confidence level using Student's $t$ test. Contours show temperature and precipitation anomalies following the colour bar scale (solid line for positive anomalies and dashed line for negative anomalies). 


\section{Pinatubo}

(a) $\Delta$ TS Year 1 (JJA)

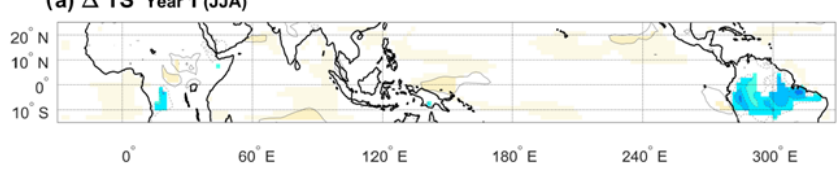

(b) $\Delta$ TS Year 1 (SON)

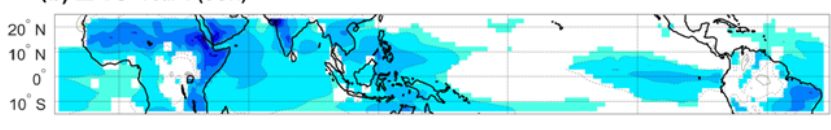

$0^{\circ}$

$60^{\circ} \mathrm{E}$

$300^{\circ} \mathrm{E}$

(e) $\triangle$ PRECIP Year 1 (JJA)

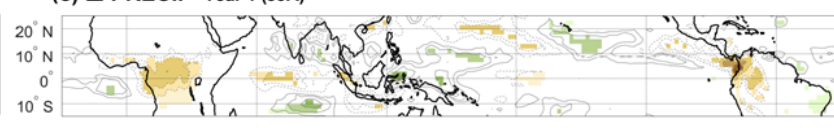

$0^{\circ} \quad 60^{\circ} \mathrm{E}$

$120^{\circ} \mathrm{E}$

$180^{\circ} \mathrm{E} \quad 240^{\circ} \mathrm{E}$

$300^{\circ} \mathrm{E}$

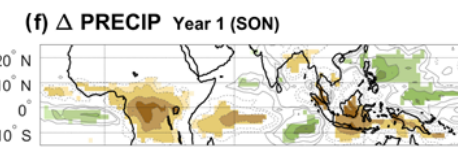

(g) $\triangle$ PRECIP Year 1 (DJF)

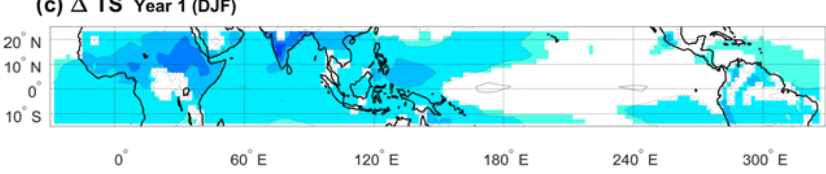

(d) $\triangle$ TS Year 1 (MAM)

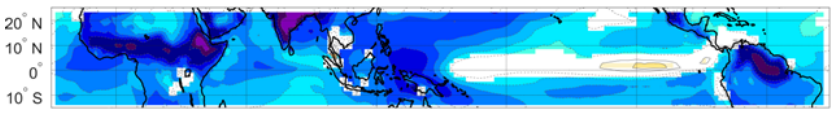

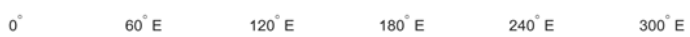

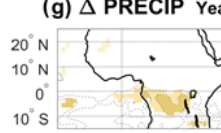

$120^{\circ} \mathrm{E}$

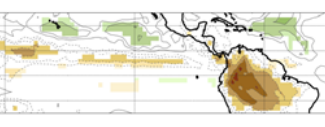

$180^{\circ} \mathrm{E} \quad 240^{\circ} \mathrm{E}$

$300^{\circ} \mathrm{E}$

(h) $\triangle$ PRECIP Year 1 (MAM)

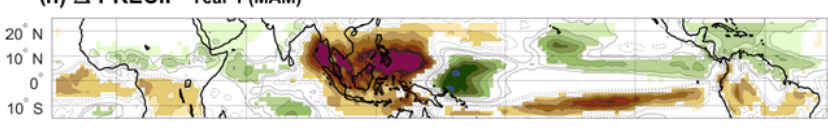

$120^{\circ} \mathrm{E}$

$180^{\circ} \mathrm{E}$
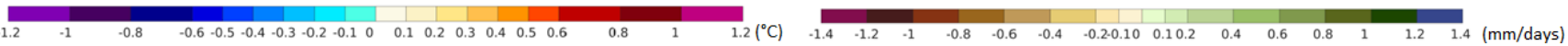

Figure A5. Ensemble mean of changes in surface temperature (a, b, c, d) and precipitation $(\mathbf{e}, \mathbf{f}, \mathbf{g}, \mathbf{h})$ between the climatology and the volcano case for each season of the year after the Pinatubo eruption. Only significant anomalies are shown with an approximate $95 \%$ confidence level using Student's $t$ test. Contours show temperature and precipitation anomalies following the colour bar scale (solid line for positive anomalies and dashed line for negative anomalies).
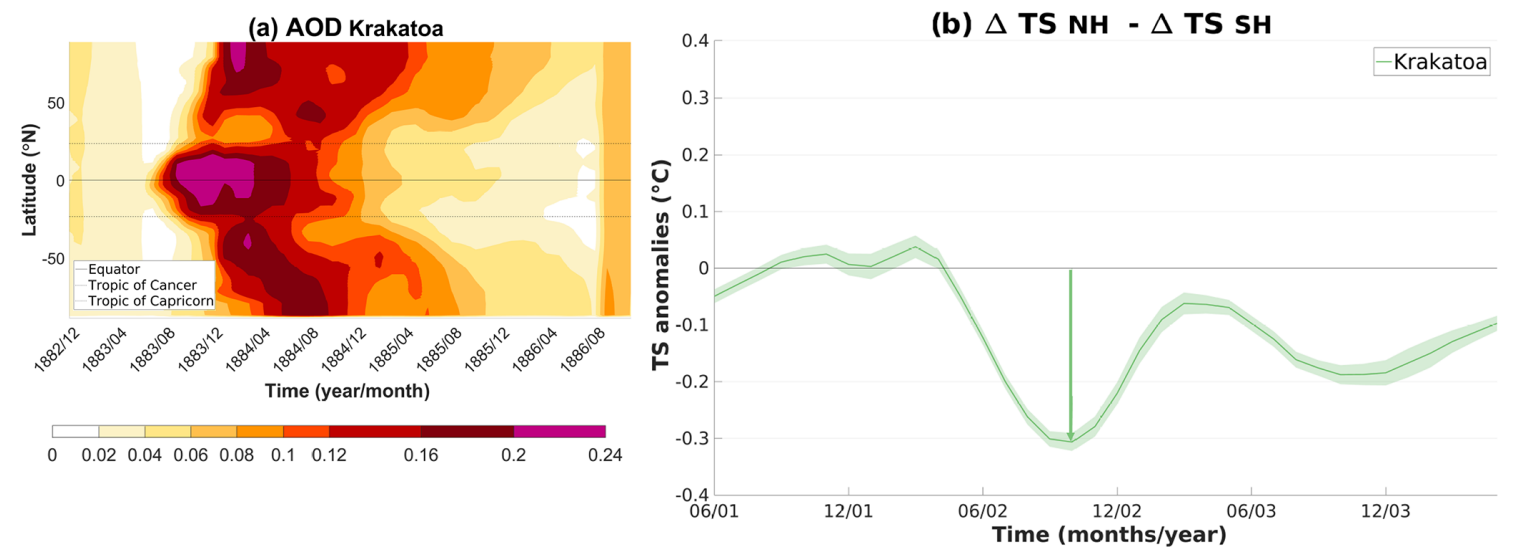

Figure A6. Evolution of the aerosol optical depth and ensemble average of the difference between the cooling of the $\mathrm{SH}(\Delta T \mathrm{SH})$ and the NH $(\Delta T \mathrm{NH})$ for the Krakatau eruption. (a) The band of wavelength used is between approximatively 462 and $625 \mathrm{~nm}$. (b) The 3year climatology is subtracted to calculate the anomalies. Shading represents twice the standard error of the ensemble mean (i.e. $\sim 95 \%$ confidence interval). 


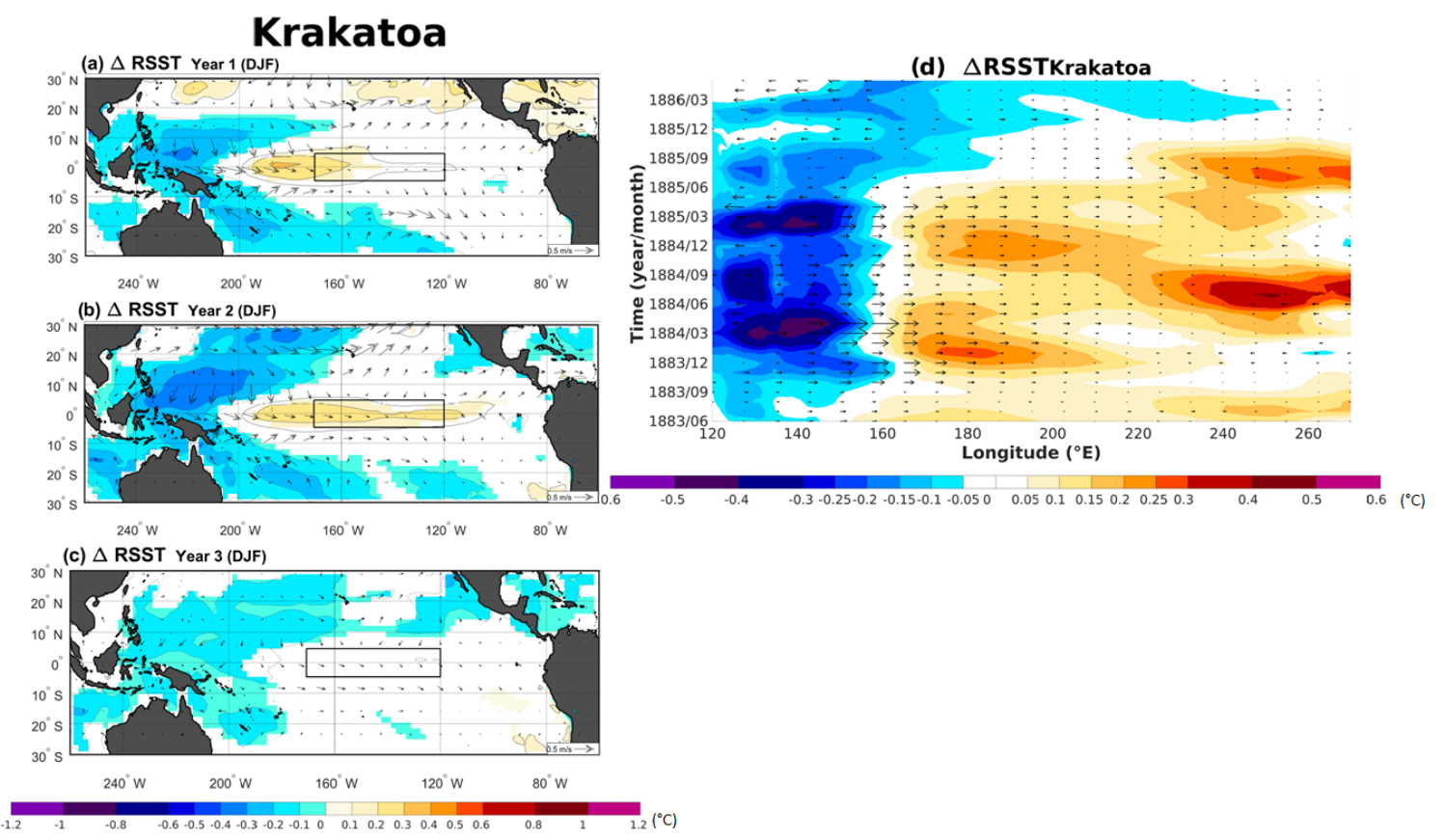

Figure A7. Ensemble mean of changes in relative sea surface temperature anomalies and $10 \mathrm{~m}$ winds (arrows) between the climatology and the volcano case for the three winter seasons (DJF) after the Krakatau eruption. Only significant RSST changes are shown with an approximate $95 \%$ confidence level using Student's $t$ test. Contours show the RSST anomalies following the colour bar scale (solid lines for positive anomalies and dashed lines for negative anomalies). The boxes indicate the Niño 3.4 area.

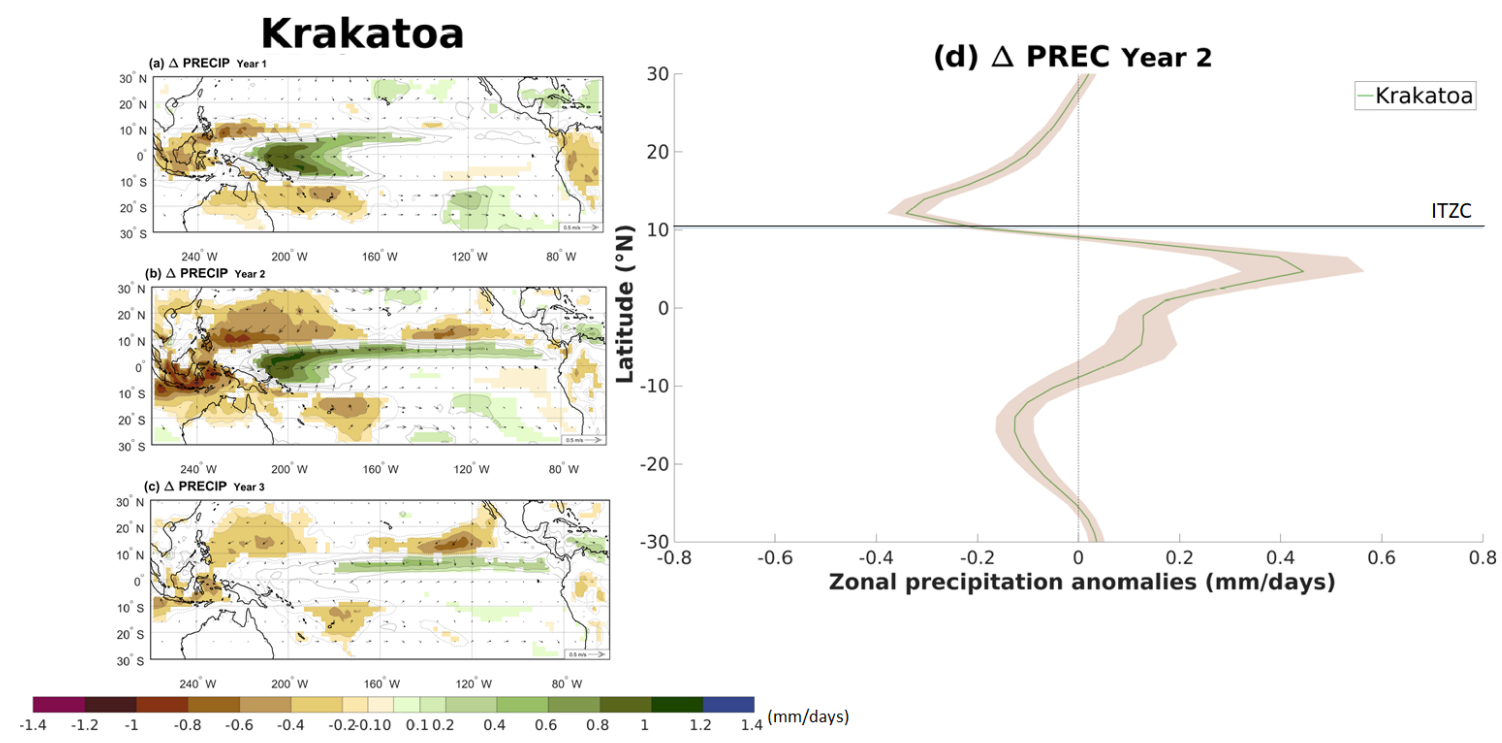

Figure A8. (a, b, c) Ensemble mean of changes in precipitation and $10 \mathrm{~m}$ wind (arrows) between the 3-year climatology and the volcano case for the three summer-to-winter seasons (June to February) following the Krakatau eruption. Only precipitation changes that are significant at the $95 \%$ confidence level using Student's $t$ test are shaded. Contours show the precipitation anomaly following the colour bar scale (solid lines for positive anomalies and dashed lines for negative anomalies; the 0 line is omitted). (d) Ensemble average of the zonal precipitation anomaly over the Pacific Ocean $\left(160^{\circ} \mathrm{E}-100^{\circ} \mathrm{W}\right)$ between the 3-year climatology and the summer-to-winter season (June to February) of the second year after the Krakatau eruption. Shading represents twice the standard error of the ensemble mean (i.e. $\sim 95 \%$ confidence interval). The blue line highlights the ensemble-averaged 3-year climatology position of the ITCZ (defined as the location of the zonalaverage precipitation maximum). 


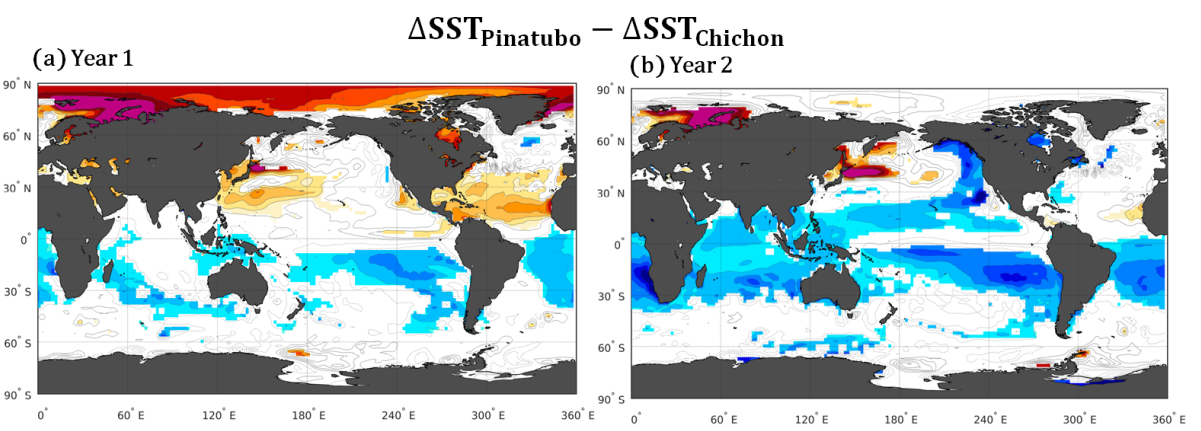

(c) Year 3

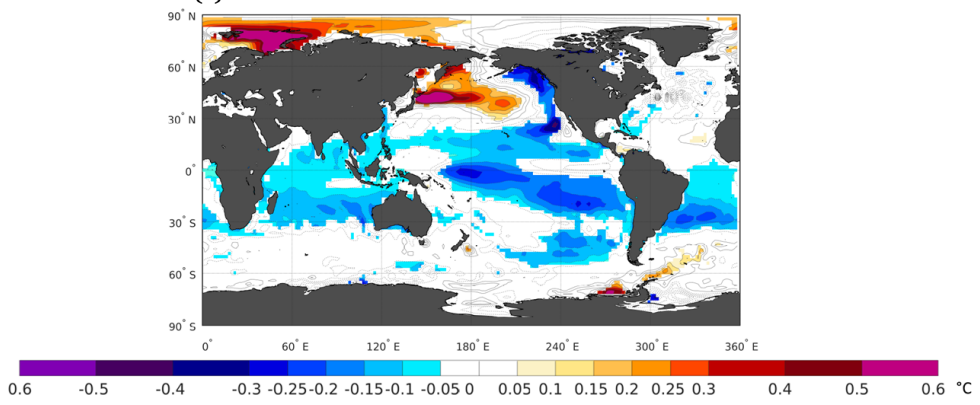

Figure A9. Difference in the ensemble mean sea surface temperature anomalies between the Pinatubo and El Chichón eruptions $\left(\Delta \mathrm{TS}_{\text {Pinatubo }}-\Delta \mathrm{TS}_{\text {Chichón }}\right)$. Only significant anomalies are shown with an approximate $95 \%$ confidence level using Student's $t$ test. Contours show temperature anomalies following the colour bar scale (solid line for positive anomalies and dashed line for negative anomalies).

$\triangle$ SLP Pear $1(J J A)$

(a) Agung

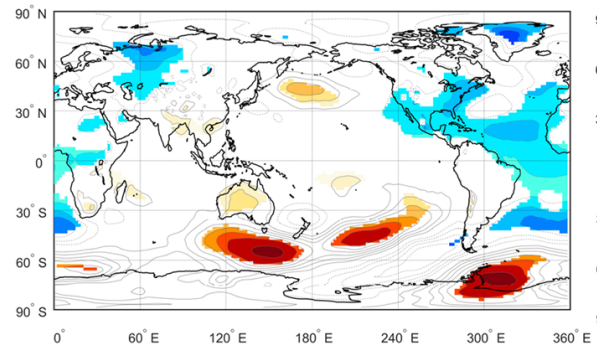

(b) Chichon

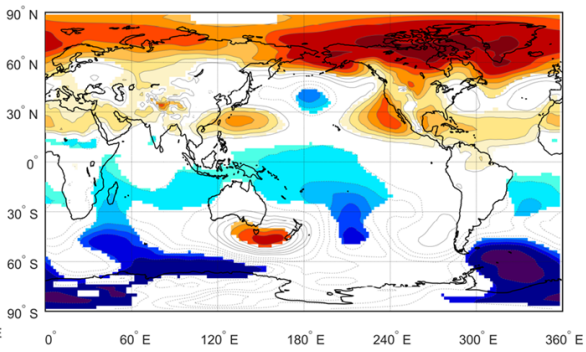

(c) Pinatubo

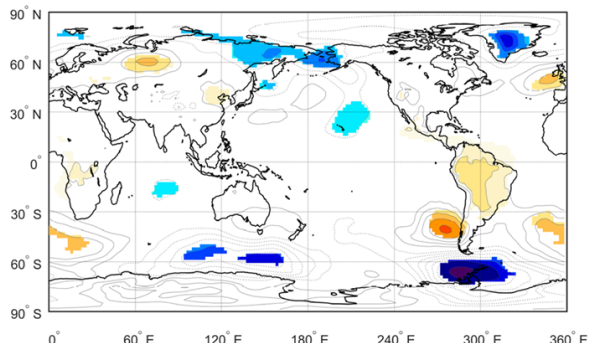

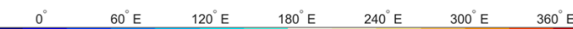

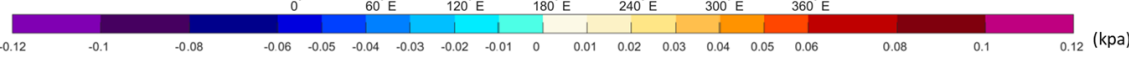

Figure A10. Ensemble average of change in the sea level pressure between the climatology and the volcano case for the first summer after the Agung (a), El Chichón (b) and Pinatubo (c) eruptions. Only significant anomalies are shown with an approximate $95 \%$ confidence level using Student's $t$ test. Contours show SLP anomalies following the colour bar scale (solid line for positive anomalies and dashed line for negative anomalies). 


\section{Agung}
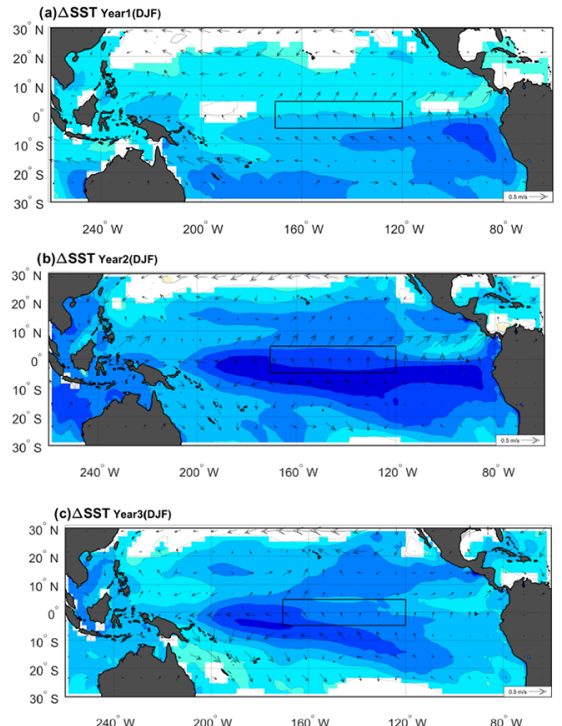

$240^{\circ}$
El Chichón

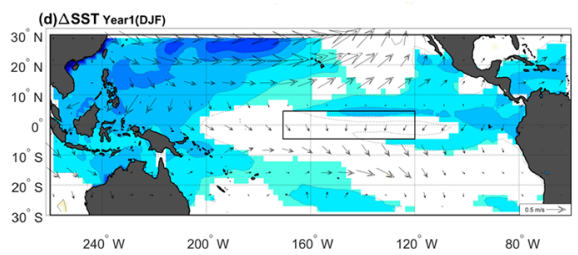

$240^{\circ} \mathrm{W}$

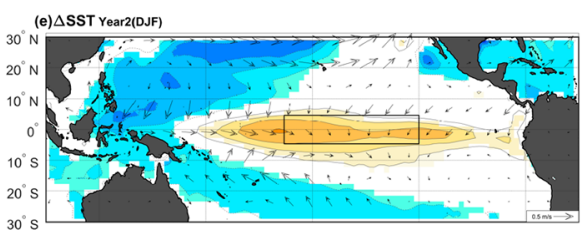

$240^{\circ} \mathrm{W}$ (f) $\triangle$ SST Year3(DJF)

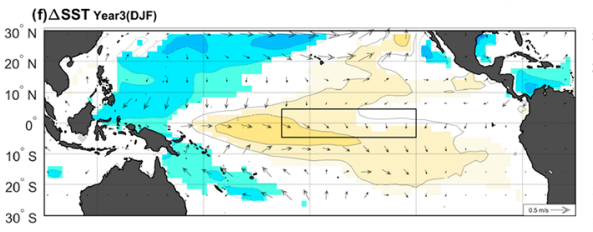

$240^{\circ} \mathrm{W} \quad 200^{\circ} \mathrm{W} \quad 160^{\circ} \mathrm{W} \quad 120^{\circ} \mathrm{W} \quad 80^{\circ} \mathrm{W}$

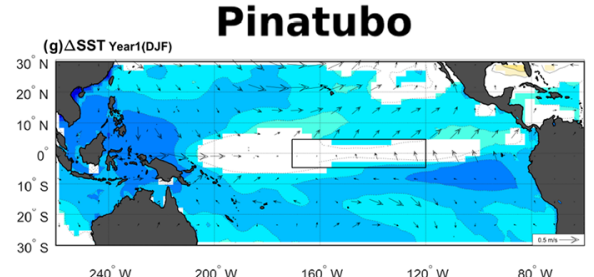

$240^{\circ} \mathrm{W}$

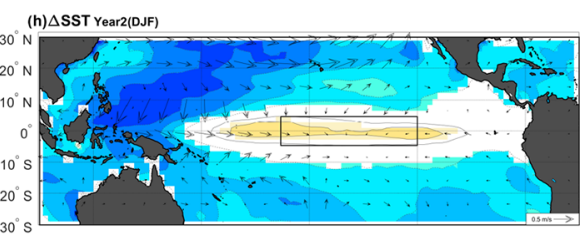

$240^{\circ} \mathrm{W}$ (i) $\Delta$ SST Year3(DJF)

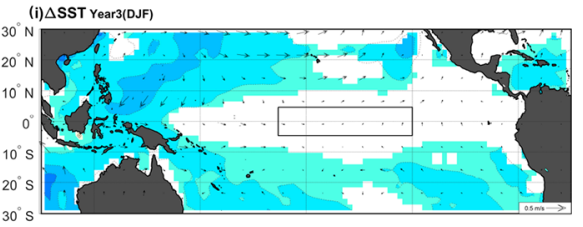

$240^{\circ} \mathrm{W}$

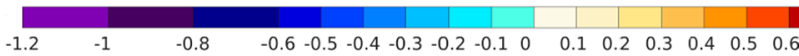

0.8

$1.2\left({ }^{\circ} \mathrm{C}\right)$

Figure A11. Ensemble mean of changes in sea surface temperature (SST) (shadings) and $10 \mathrm{~m}$ winds (arrows) between the volcano case and the climatology for each of the following three winter seasons (DJF) after the Agung (a-c), El Chichón (d-f) and Pinatubo (g-i) eruptions. Only significant SST changes are shaded with an approximate $95 \%$ confidence level using Student's $t$ test. Contours show the SST anomalies following the colour bar scale (solid lines for positive anomalies and dashed lines for negative anomalies; the 0 line is omitted). The boxes indicate the Niño 3.4 area.
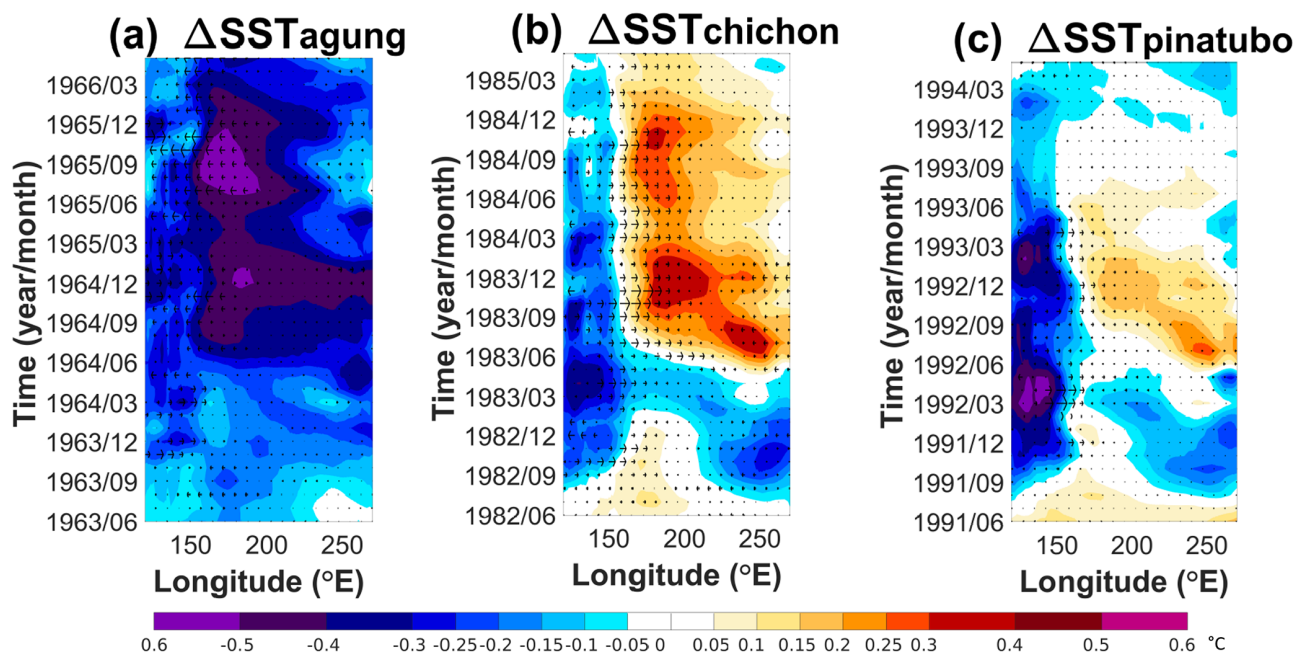

Figure A12. Hovmöller plot of the ensemble mean of the SST anomalies in the equatorial Pacific (averaged over -5 and $5^{\circ} \mathrm{N}$ ) and the change in the zonal component of the $10 \mathrm{~m}$ winds $(\mathrm{m} / \mathrm{s})$ for the 3 years following each eruption. The anomalies are calculated relative to the 3 years before each eruption. 


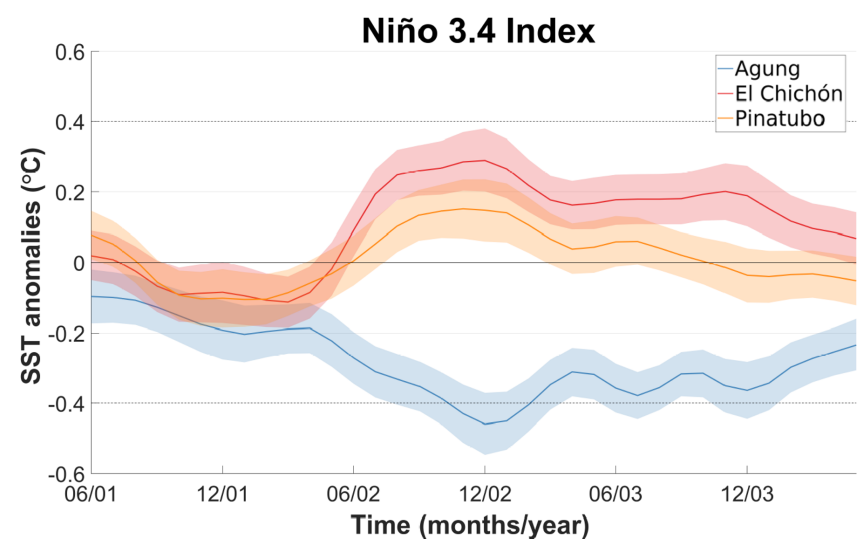

Figure A13. Ensemble mean changes in the Niño 3.4 index after each eruption. The 3-year climatology is subtracted to calculate the anomalies. Shading represents twice the standard error of the mean using an approximate $95 \%$ confidence interval.

\section{Agung}
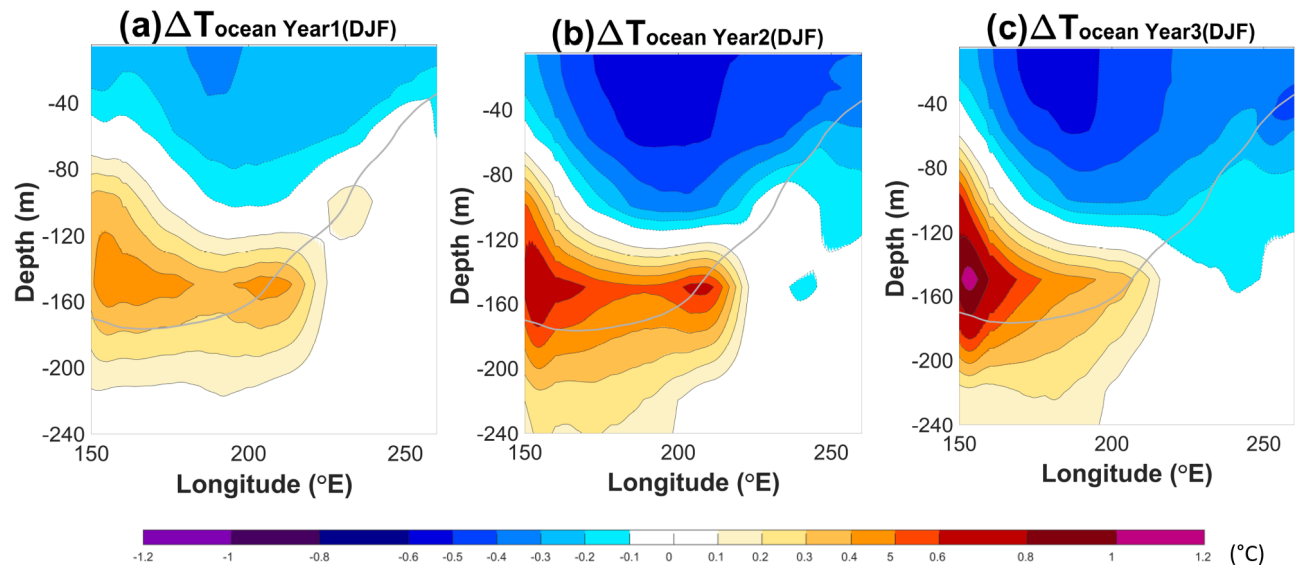

Figure A14. Ensemble mean changes shown for a transect in the equatorial Pacific (averaged $5^{\circ} \mathrm{N}-5^{\circ} \mathrm{S}$ ) of the ocean temperature (shadings) between the volcano case and the climatology for each of the following three winter seasons (DJF) after the Agung eruption. Contours show the SST anomalies following the colour bar scale (solid lines for positive anomalies and dashed lines for negative anomalies; the 0 line is omitted). The bold grey line shows the climatological thermocline depth (as defined using the $20^{\circ} \mathrm{C}$ isotherm). This is shown for 100 ensemble members. 


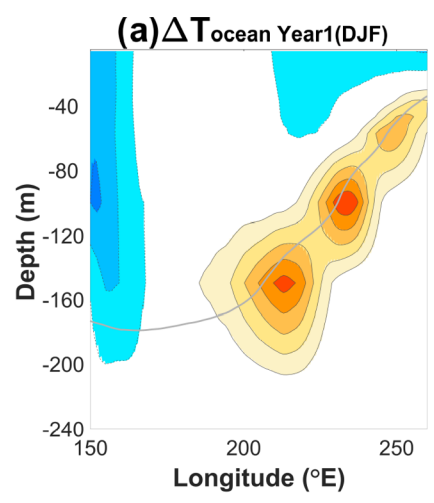

\section{El Chichón}

(b) $\Delta T_{\text {ocean }}$ Year2(DJF)

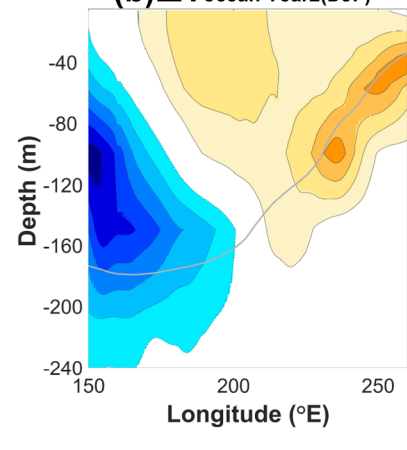

(c) $\Delta T_{\text {ocean }}$ Year3(DJF)

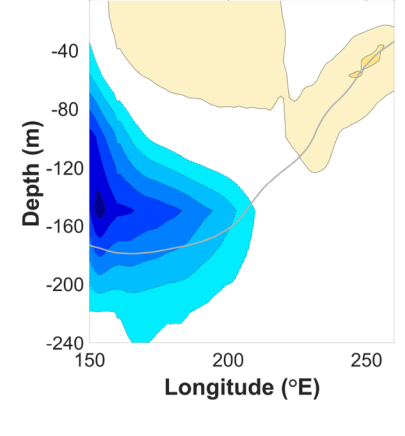

Figure A15. Ensemble mean changes shown for a transect in the equatorial Pacific (averaged $5^{\circ} \mathrm{N}-5^{\circ} \mathrm{S}$ ) of the ocean temperature (shadings) between the volcano case and the climatology for each of the following three winter seasons (DJF) after the Chichón eruption. Contours show the SST anomalies following the colour bar scale (solid lines for positive anomalies and dashed lines for negative anomalies; the 0 line is omitted). The bold grey line shows the climatological thermocline depth (as defined using the $20^{\circ} \mathrm{C}$ isotherm). This is shown for 100 ensemble members.

(a) $\Delta T_{\text {ocean Year1(DJF) }}$

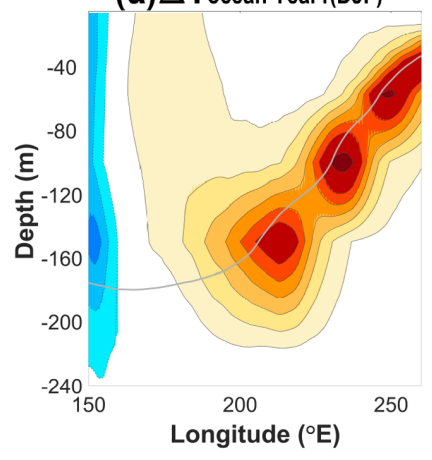

\section{Pinatubo}

(b) $\Delta T_{\text {ocean }}$ Year2(DJF)

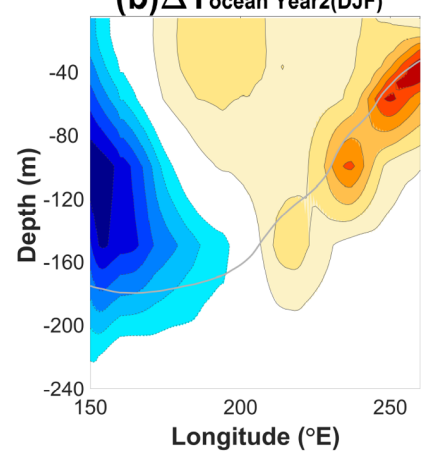

(c) $\Delta T_{\text {ocean }}$ Year3(DJF)

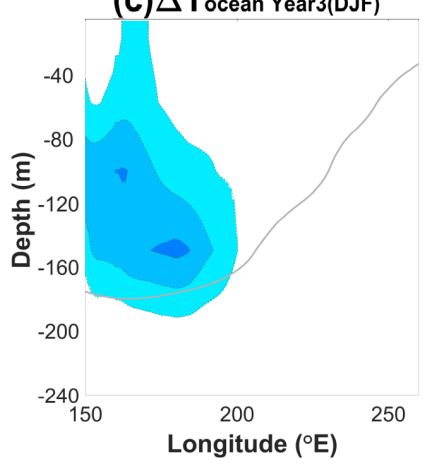

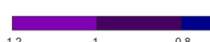

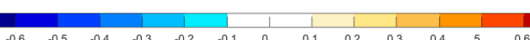

Figure A16. Ensemble mean changes shown for a transect in the equatorial Pacific (averaged $5^{\circ} \mathrm{N}-5^{\circ} \mathrm{S}$ ) of the ocean temperature (shadings) between the volcano case and the climatology for each of the following three winter seasons (DJF) after the Pinatubo eruption. Contours show the SST anomalies following the colour bar scale (solid lines for positive anomalies and dashed lines for negative anomalies; the 0 line is omitted). The bold grey line shows the climatological thermocline depth (as defined using the $20^{\circ} \mathrm{C}$ isotherm). This is shown for 100 ensemble members. 


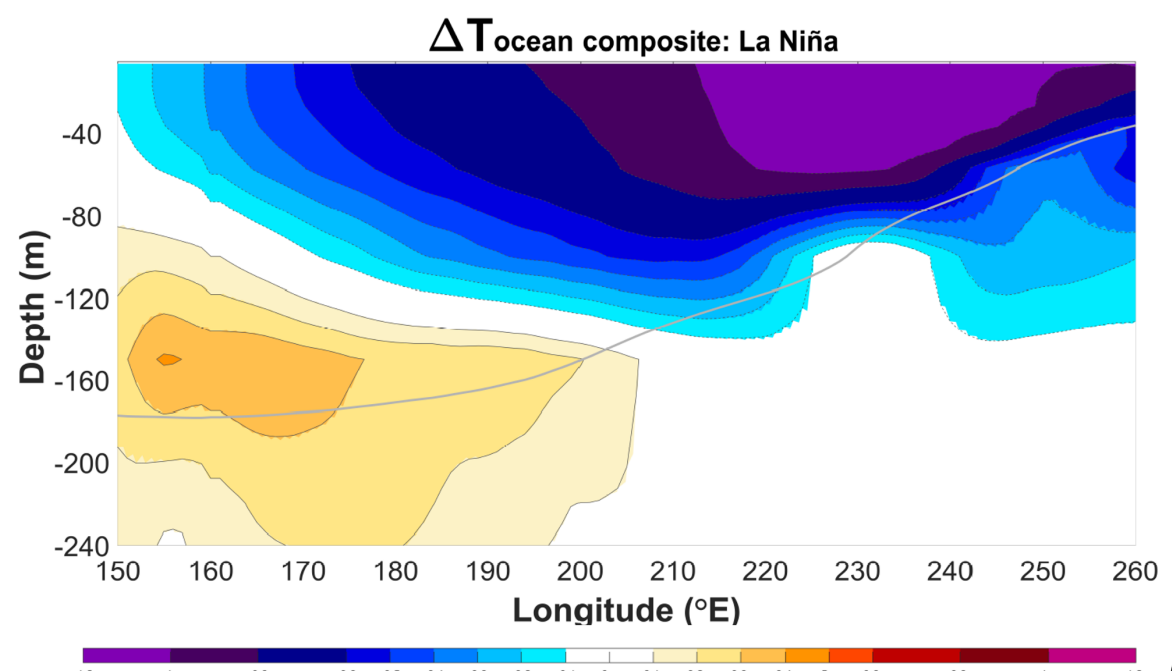

$\left({ }^{\circ} \mathrm{C}\right)$

Figure A17. Temperature composite of La Niña events (Niño3.4 index $\leq 0.4^{\circ} \mathrm{C}$ ) for a transect in the equatorial Pacific (averaged between $5^{\circ} \mathrm{S}$ and $5^{\circ} \mathrm{N}$ ) in the reference period of each eruption (4 years before each eruption) and for the winter season (DJF). A total of $100 \mathrm{ensemble}$ members are considered, leading to a total of 1200 years as a reference period and 237 La Niña events. Contours show the SST anomalies following the colour bar scale (solid lines for positive anomalies and dashed lines for negative anomalies; the 0 line is omitted). The bold grey line shows the climatological thermocline depth (as defined using the $20^{\circ} \mathrm{C}$ isotherm).

\section{A1 Model validation}

Our model simulates a global cooling around $0.2-0.4^{\circ} \mathrm{C}$ following the three major eruptions investigated in the study (Agung, El Chichón and Pinatubo). Robock and Mao (1995) provided an estimate for the cooling following these large volcanic eruptions to be of a similar magnitude as those simulated by our model. Our model also reproduces the highlatitude winter warming after El Chichón and Pinatubo with temperature anomalies locally exceeding $2{ }^{\circ} \mathrm{C}$.

(a) $\Delta$ SST $_{\text {Agung }}$

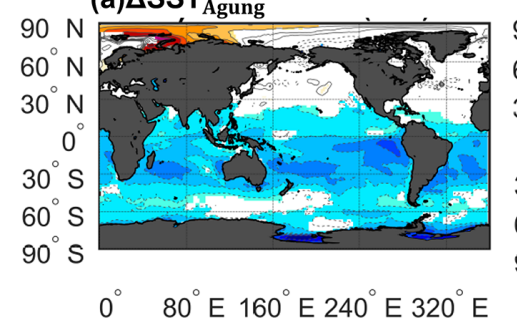

(b) $\Delta S S T_{\text {Chichon }}$

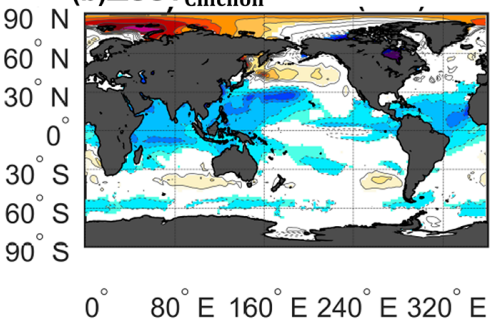

(c) $\Delta S S T_{\text {Pinatubo }}$

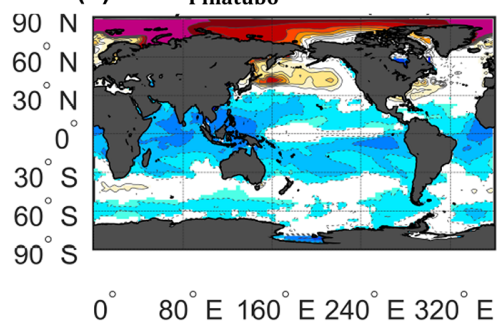

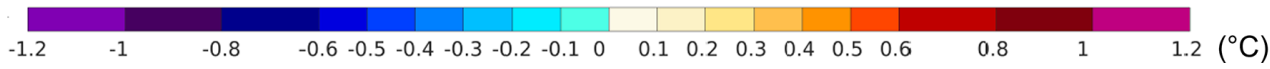

Figure A18. Ensemble mean of changes in sea surface temperature (SST) (shadings) between the volcano case and the climatology for the year following the Agung $(\mathbf{a}-\mathbf{c})$, El Chichón $(\mathbf{d}-\mathbf{f})$ and Pinatubo (g-i) eruptions. Contours show the SST anomalies following the colour bar scale (solid lines for positive anomalies and dashed lines for negative anomalies; the 0 line is omitted). 
Code availability. The codes used to analyse the data are available from the corresponding author on reasonable request.

Data availability. The first 100 ensembles generated and analysed in this study are available at https://mpimet.mpg.de/en/ grand-ensemble/ (Max-Planck-Institut für Meteorologie, 2021). The other 100 ensembles are available from the corresponding author on reasonable request. All data needed to evaluate the conclusions in the paper are present in the paper. Additional data related to this paper may be requested from the authors.

Author contributions. BW analysed the model output and wrote the manuscript with the support of FSRP and NM. FSRP conceived the study and supervised the findings of this work. NM provided the model output. All authors contributed to the interpretation of the results and the writing of the manuscript.

Competing interests. The authors declare that they have no conflict of interest.

Disclaimer. Publisher's note: Copernicus Publications remains neutral with regard to jurisdictional claims in published maps and institutional affiliations.

Acknowledgements. We thank Mikhail Dobrynin and Johanna Baehr from the University of Hamburg for completing the second set of 100 ensembles from the MPI-GE simulation and providing the data from these simulations for use in this paper.

Financial support. Benjamin Ward and Francesco S. R. Pausata have been supported by the Natural Sciences and Engineering Research Council of Canada (grant no. RGPIN201804981) and the Fonds de recherche du Québec-Nature et technologies (grant no. 2020NC268559). Nicola Maher has been supported by the Max Planck Society for the Advancement of Science and the Alexander von Humboldt Foundation. Nicola Maher has been supported by the Max Planck Society for the Advancement of Science, the Alexander von Humboldt Foundation and the Cooperative Institute for Research in Environmental Sciences (CIRES) at CU Boulder.

Review statement. This paper was edited by Ben Kravitz and reviewed by three anonymous referees.

\section{References}

Adams, J. B., Mann, M. E., and Ammann, C. M.: Proxy evidence for an El Niño-like response to volcanic forcing, Nature, 426, 274-278, https://doi.org/10.1038/nature02101, 2003.

Anchukaitis, K. J., Breitenmoser, P., Briffa, K. R., Buchwal, A., Büntgen, U., Cook, E. R., D’Arrigo, R. D., Esper, J., Evans,
M. N., Frank, D., Grudd, H., Gunnarson, B. E., Hughes, M. K., Kirdyanov, A. V., Körner, C., Krusic, P. J., Luckman, B., Melvin, T. M., Salzer, M. W., Shashkin, A. V., Timmreck, C., Vaganov, E. A., and Wilson, R. J. S.: Tree rings and volcanic cooling, Nat. Geoci., 5, 836-837, https://doi.org/10.1038/ngeo1645, 2012.

Barnes, J. E. and Hofmann, D. J.: Lidar measurements of stratospheric aerosol over Mauna Loa Observatory, Geophys. Res. Lett., 24, 1923-1926, https://doi.org/10.1029/97GL01943, 1997.

Bittner, M., Schmidt, H., Timmreck, C., and Sienz, F.: Using a large ensemble of simulations to assess the Northern Hemisphere stratospheric dynamical response to tropical volcanic eruptions and its uncertainty, Geophys. Res. Lett., 43, 93249332, https://doi.org/10.1002/2016GL070587, 2016.

Bjerknes, J.: Atmospheric Teleconnections From the Equatorial Pacific, Mon. Weather Rev., 97, 163-172, 1969.

Bluth, G. J. S., Doiron, S. D., Schnetzler, C. C., Krueger, A. J., and Walter, L. S.: Global tracking of the $\mathrm{SO}_{2}$ clouds from the June, 1991 Mount Pinatubo eruptions, Geophys. Res. Lett., 19, 151154, https://doi.org/10.1029/91GL02792, 1992.

Choi, W., Grant, W. B., Park, J. H., Lee, K.-M., Lee, H., and Russell, J. M.: Role of the quasi-biennial oscillation in the transport of aerosols from the tropical stratospheric reservoir to midlatitudes, J. Geophys. Res.-Atmos., 103, 6033-6042, https://doi.org/10.1029/97JD03118, 1998.

Christiansen, B.: Volcanic eruptions, large-scale modes in the Northern Hemisphere, and the El Niño-Southern Oscillation, J. Climate, 21, 910-922, https://doi.org/10.1175/2007JCLI1657.1, 2008.

Clement, A. C., Seager, R., Cane, M. A., and Zebiak, S. E.: An ocean dynamical thermostat, J. Climate, 9, 2190-2196, https://doi.org/10.1175/15200442(1996)009<2190:AODT>2.0.CO;2, 1996.

Colose, C. M., LeGrande, A. N., and Vuille, M.: Hemispherically asymmetric volcanic forcing of tropical hydroclimate during the last millennium, Earth Syst. Dynam., 7, 681-696, https://doi.org/10.5194/esd-7-681-2016, 2016.

D’Arrigo, R., Cook, E. R., Wilson, R. J., Allan, R., and Mann, M. E.: On the variability of ENSO over the past six centuries, Geophys. Res. Lett., 32, 1-4, https://doi.org/10.1029/2004GL022055, 2005.

Dee, S. G., Cobb, K. M., Emile-Geay, J., Ault, T. R., Lawrence Edwards, R., Cheng, H., and Charles, C. D.: No consistent ENSO response to volcanic forcing over the last millennium, Science, 367, 1477-1481, https://doi.org/10.1126/science.aax2000, 2020.

Ding, Y., Carton, J. A., Chepurin, G. A., Stenchikov, G., Robock, A., Sentman, L. T., and Krasting, J. P.: Ocean response to volcanic eruptions in Coupled Model Intercomparison Project 5 simulations, J. Geophys. Res.-Ocean., 119, 5622-5637, https://doi.org/10.1002/2013JC009780, 2014.

Driscoll, S., Bozzo, A., Gray, L. J., Robock, A., and Stenchikov, G.: Coupled Model Intercomparison Project 5 (CMIP5) simulations of climate following volcanic eruptions, J. Geophys. Res.Atmos., 117, 17105, https://doi.org/10.1029/2012JD017607, 2012.

Eddebbar, Y. A., Rodgers, K. B., Long, M. C., Subramanian, A. C., Xie, S. P., and Keeling, R. F.: El Niño-like physical and biogeochemical ocean response to tropical eruptions, J. Climate, 32, 2627-2649, https://doi.org/10.1175/JCLI-D-18-0458.1, 2019. 
Emile-Geay, J., Seager, R., Cane, M. A., Cook, E. R., and Haug, G. H.: Volcanoes and ENSO over the past millennium, J. Climate, 21, 3134-3148, https://doi.org/10.1175/2007JCLI1884.1, 2008.

Fasullo, J. T., Tomas, R., Stevenson, S., Otto-Bliesner, B., Brady, E., and Wahl, E.: The amplifying influence of increased ocean stratification on a future year without a summer, Nat. Commun., 8, 1-10, https://doi.org/10.1038/s41467-017-01302-z, 2017.

Giorgetta, M. A., Jungclaus, J., Reick, C. H., Legutke, S., Bader, J., Böttinger, M., Brovkin, V., Crueger, T., Esch, M., Fieg, K., Glushak, K., Gayler, V., Haak, H., Hollweg, H.-D., Ilyina, T., Kinne, S., Kornblueh, L., Matei, D., Mauritsen, T., Mikolajewicz, U., Mueller, W., Notz, D., Pithan, F., Raddatz, T., Rast, S., Redler, R., Roeckner, E., Schmidt, H., Schnur, R., Segschneider, J., Six, K. D., Stockhause, M., Timmreck, C., Wegner, J., Widmann, H., Wieners, K.-H., Claussen, M., Marotzke, J., and Stevens, B.: Climate and carbon cycle changes from 1850 to 2100 in MPI-ESM simulations for the Coupled Model Intercomparison Project phase 5, J. Adv. Model. Earth Sy., 5, 572-597, https://doi.org/10.1002/jame.20038, 2013.

Harshvardhan, M. R.: Perturbation of the Zonal Radiation Balance by a Stratospheric Aerosol Layer, J. Atmos. Sci., 36, 1274-1285, 1979.

Iles, C. E., Hegerl, G. C., Schurer, A. P., and Zhang, X.: The effect of volcanic eruptions on global precipitation, J. Geophys. Res.Atmos., 118, 8770-8786, https://doi.org/10.1002/jgrd.50678, 2013.

Illing, S., Kadow, C., Pohlmann, H., and Timmreck, C.: Assessing the impact of a future volcanic eruption on decadal predictions, Earth Syst. Dynam., 9, 701-715, https://doi.org/10.5194/esd-9701-2018, 2018.

Kang, S. M., Held, I. M., Frierson, D. M. W., and Zhao, M.: The response of the ITCZ to extratropical thermal forcing: Idealized slab-ocean experiments with a GCM, J. Climate, 21, 3521-3532, https://doi.org/10.1175/2007JCLI2146.1, 2008.

Khodri, M., Izumo, T., Vialard, J., Janicot, S., Cassou, C., Lengaigne, M., Mignot, J., Gastineau, G., Guilyardi, E., Lebas, N., Robock, A., and McPhaden, M. J.: Tropical explosive volcanic eruptions can trigger El Ninõ by cooling tropical Africa, Nat. Commun., 8, 1-13, https://doi.org/10.1038/s41467-01700755-6, 2017.

Kodera, K.: Influence of volcanic eruptions on the troposphere through stratospheric dynamical processes in the Northern Hemisphere winter, J. Geophys. Res., 99, 1273-1282, https://doi.org/10.1029/93JD02731, 1994.

Li, J., Xie, S. P., Cook, E. R., Morales, M. S., Christie, D. A., Johnson, N. C., Chen, F., D'Arrigo, R., Fowler, A. M., Gou, X., and Fang, K.: El Niño modulations over the past seven centuries, Nat. Clim. Change, 3, 822-826, https://doi.org/10.1038/nclimate1936, 2013.

Lim, H. G., Yeh, S. W., Kug, J. S., Park, Y. G., Park, J. H., Park, R., and Song, C. K.: Threshold of the volcanic forcing that leads the El Niño-like warming in the last millennium: results from the ERIK simulation, Clim. Dynam., 11, 3725-3736, https://doi.org/10.1007/s00382-015-2799-3, 2016.

Liu, F., Li, J., Wang, B., Liu, J., Li, T., Huang, G., and Wang, Z.: Divergent El Niño responses to volcanic eruptions at different latitudes over the past millennium, Clim. Dynam., 50, 3799-3812, https://doi.org/10.1007/s00382-017-3846-z, 2018.
Maher, N., McGregor, S., England, M. H., and Gupta, A. Sen: Effects of volcanism on tropical variability, Geophys. Res. Lett., 42, 6024-6033, https://doi.org/10.1002/2015GL064751, 2015.

Maher, N., Milinski, S., Suarez-Gutierrez, L., Botzet, M., Dobrynin, M., Kornblueh, L., Kröger, J., Takano, Y., Ghosh, R., Hedemann, C., Li, C., Li, H., Manzini, E., Notz, D., Putrasahan, D., Boysen, L., Claussen, M., Ilyina, T., Olonscheck, D., Raddatz, T., Stevens, B., and Marotzke, J.: The Max Planck Institute Grand Ensemble - Enabling the Exploration of Climate System Variability, J. Adv. Model. Earth Sy., 11, 2050-2069, https://doi.org/10.1029/2019MS001639, 2019.

Man, W., Zhou, T., and Jungclaus, J. H.: Effects of large volcanic eruptions on global summer climate and east asian monsoon changes during the last millennium: Analysis of MPI-ESM simulations, J. Climate, 27, 7394-7409, https://doi.org/10.1175/JCLID-13-00739.1, 2014.

Mann, M. E., Cane, M. A., Zebiak, S. E., and Clement, A.: Volcanic and solar forcing of the tropical Pacific over the past 1000 years, J. Climate, 18, 447-456, https://doi.org/10.1175/JCLI-3276.1, 2005.

Max-Planck-Institut für Meteorologie: Grand Ensemble, available at: https://mpimet.mpg.de/en/grand-ensemble/, last access: 15 September 2021.

McGregor, S. and Timmermann, A.: The effect of explosive tropical volcanism on ENSO, J. Climate, 24, 2178-2191, https://doi.org/10.1175/2010JCLI3990.1, 2011.

McGregor, S., Timmermann, A., and Timm, O.: A unified proxy for ENSO and PDO variability since 1650, Clim. Past, 6, 1-17, https://doi.org/10.5194/cp-6-1-2010, 2010.

McGregor, S., Khodri, M., Maher, N., Ohba, M., Pausata, F. S. R., and Stevenson, S.: The Effect of Strong Volcanic Eruptions on ENSO, ENSO Chang. Clim., 12, 267-287, https://doi.org/10.1002/9781119548164.ch12, 2020.

Milinski, S., Maher, N., and Olonscheck, D.: How large does a large ensemble need to be?, Earth Syst. Dynam., 11, 885-901, https://doi.org/10.5194/esd-11-885-2020, 2020.

Nicholls, N.: Low latitude volcanic eruptions and the El Niño-Southern Oscillation, J. Climatol., 8, 91-95, https://doi.org/10.1002/joc.3370080109, 1988.

Ohba, M., Shiogama, H., Yokohata, T., and Watanabe, M.: Impact of Strong Tropical Volcanic Eruptions on ENSO Simulated in a Coupled GCM, J. Climate, 26, 5169-5182, https://doi.org/10.1175/JCLI-D-12-00471.1, 2013.

Paik, S., Min, S. K., Iles, C. E., Fischer, E. M., and Schurer, A. P.: Volcanic-induced global monsoon drying modulated by diverse El Ninõ responses, Sci. Adv., 6, eaba1212, https://doi.org/10.1126/sciadv.aba1212, 2020.

Pausata, F. S. R., Grini, A., Caballero, R., Hannachi, A., and Seland, $\varnothing .:$ High-latitude volcanic eruptions in the Norwegian Earth System Model: The effect of different initial conditions and of the ensemble size, Tellus, B, 67, 26728, https://doi.org/10.3402/tellusb.v67.26728, 2015a.

Pausata, F. S. R., Chafik, L., Caballero, R., and Battisti, D. S.: Impacts of high-latitude volcanic eruptions on ENSO and AMOC, P. Natl. Acad. Sci. USA, 112, 13784-13788, https://doi.org/10.1073/pnas.1509153112, 2015b.

Pausata, F. S. R., Karamperidou, C., Caballero, R., and Battisti, D. S.: ENSO response to high-latitude volcanic eruptions in the Northern Hemisphere: The role of the 
initial conditions, Geophys. Res. Lett., 43, 8694-8702, https://doi.org/10.1002/2016GL069575, 2016.

Pausata, F. S. R., Zanchettin, D., Karamperidou, C., Caballero, R., and Battisti, D. S.: ITCZ shift and extratropical teleconnections drive ENSO response to volcanic eruptions, Sci. Adv., 6, eaaz5006, https://doi.org/10.1126/SCIADV.AAZ5006, 2020.

Pinto, J. P., Turco, R. P., and Toon, O. B.: Self-limiting physical and chemical effects in volcanic eruption clouds, J. Geophys. Res., 94, 11165-11174, https://doi.org/10.1029/jd094id08p11165, 1989.

Pollack, J. B., Toon, O. B., Sagan, C., Summers, A., Baldwin, B., and Van Camp, W.: Volcanic explosions and climatic change: A theoretical assessment, J. Geophys. Res., 81, 1071-1083, https://doi.org/10.1029/jc081i006p01071, 1976.

Predybaylo, E., Stenchikov, G., Wittenberg, A. T., and Zeng, F.: Impacts of a pinatubo-size volcanic eruption on ENSO, J. Geophys. Res., 122, 925-947, https://doi.org/10.1002/2016JD025796, 2017.

Predybaylo, E., Stenchikov, G., Wittenberg, A. T., and Osipov, S.: El Niño/Southern Oscillation response to lowlatitude volcanic eruptions depends on ocean pre-conditions and eruption timing, Commun. Earth Environ., 1, 1-13, https://doi.org/10.1038/s43247-020-0013-y, 2020.

Rampino, M. R. and Self, S.: Sulphur-rich volcanic eruptions and stratospheric aerosols, Nature, 310, 677-679, https://doi.org/10.1038/310677a0, 1984.

Robock, A.: Volcanic eruptions and climate, Rev. Geophys., 38, 191-219, https://doi.org/10.1029/1998RG000054, 2000.

Robock, A. and Liu, Y.: The volcanic signal in Goddard Institute for Space Studies three- dimensional model simulations, J. Climate, 7, 44-55, https://doi.org/10.1175/15200442(1994)007<0044:TVSIGI>2.0.CO;2, 1994.

Robock, A. and Mao, J.: The volcanic signal in surface temperature observations, J. Climate, $8, \quad 1086-1103$, https://doi.org/10.1175/15200442(1995)008<1086:TVSIST>2.0.CO;2, 1995.

Schmidt, H., Rast, S., Bunzel, F., Esch, M., Giorgetta, M., Kinne, S., Krismer, T., Stenchikov, G., Timmreck, C., Tomassini, L., and Walz, M.: Response of the middle atmosphere to anthropogenic and natural forcings in the CMIP5 simulations with the Max Planck Institute Earth system model, J. Adv. Model. Earth Sy., 5, 98-116, https://doi.org/10.1002/JAME.20014, 2013.

Schneider, T., Bischoff, T., and Haug, G. H.: Migrations and dynamics of the intertropical convergence zone, Nature, 513, 4553, https://doi.org/10.1038/nature13636, 2014.

Self, S. and Rampino, M. R.: The 1963-1964 eruption of Agung volcano (Bali, Indonesia), Bull. Volcanol., 74, 1521-1536, https://doi.org/10.1007/s00445-012-0615-z, 2012.

Self, S., Rampino, M. R., Zhao, J., and Katz, M. G.: Volcanic aerosol perturbations and strong El Niño events: No general correlation, Geophys. Res. Lett., 24, 1247-1250, https://doi.org/10.1029/97GL01127, 1997.

Stenchikov, G., Hamilton, K., Stouffer, R. J., Robock, A., Ramaswamy, V., Santer, B., and Graf, H. F.: Arctic Oscillation response to volcanic eruptions in the IPCC AR4 climate models, J. Geophys. Res.-Atmos., 111, D07107, https://doi.org/10.1029/2005JD006286, 2006.

Stenchikov, G. L., Kirchner, I., Robock, A., Graf, H. F., Antuña, J. C., Grainger, R. G., Lambert, A., and Thomason,
L.: Radiative forcing from the 1991 Mount Pinatubo volcanic eruption, J. Geophys. Res.-Atmos., 103, 13837-13857 https://doi.org/10.1029/98JD00693, 1998.

Stevenson, S., Otto-Bliesner, B., Fasullo, J., and Brady, E.: "El Niño Like" hydroclimate responses to last millennium volcanic eruptions, J. Climate, 29, 2907-2921, https://doi.org/10.1175/JCLID-15-0239.1, 2016.

Stevenson, S., Fasullo, J. T., Otto-Bliesner, B. L., Tomas, R. A., and Gao, C.: Role of eruption season in reconciling model and proxy responses to tropical volcanism, P. Natl. Acad. Sci. USA, 114, 1822-1826, https://doi.org/10.1073/pnas.1612505114, 2017.

Stoffel, M., Khodri, M., Corona, C., Guillet, S., Poulain, V., Bekki, S., Guiot, J., Luckman, B. H., Oppenheimer, C., Lebas, N., Beniston, M., and Masson-Delmotte, V.: Estimates of volcanic-induced cooling in the Northern Hemisphere over the past 1,500 years, Nat. Geosci., 8, 784-788, https://doi.org/10.1038/ngeo2526, 2015.

Suarez-Gutierrez, L., Milinski, S., and Maher, N.: Exploiting large ensembles for a better yet simpler climate model evaluation, Clim. Dynam., 1, 1-24, https://doi.org/10.1007/S00382-02105821-W, 2021.

Sun, W., Liu, J., Wang, B., Chen, D., Liu, F., Wang, Z., Ning, L., and Chen, M.: A "La Niña-like" state occurring in the second year after large tropical volcanic eruptions during the past 1500 years, Clim. Dynam., 52, 7495-7509, https://doi.org/10.1007/s00382018-4163-x, 2019.

Thompson, D. W. J., Wallace, J. M., Jones, P. D., and Kennedy, J. J.: Identifying signatures of natural climate variability in time series of global-mean surface temperature: Methodology and insights, J. Climate, 22, 6120-6141, https://doi.org/10.1175/2009JCLI3089.1, 2009.

Timmreck, C.: Modeling the climatic effects of large explosive volcanic eruptions, WIRES Clim. Change, 3, 545-564, https://doi.org/10.1002/wcc.192, 2012.

Timmreck, C., Pohlmann, H., Illing, S., and Kadow, C.: The impact of stratospheric volcanic aerosol on decadalscale climate predictions, Geophys. Res. Lett., 43, 834-842, https://doi.org/10.1002/2015GL067431, 2016.

Toohey, M., Krüger, K., Niemeier, U., and Timmreck, C.: The influence of eruption season on the global aerosol evolution and radiative impact of tropical volcanic eruptions, Atmos. Chem. Phys., 11, 12351-12367, https://doi.org/10.5194/acp-11-123512011, 2011.

Trenberth, K. E. and Dai, A.: Effects of Mount Pinatubo volcanic eruption on the hydrological cycle as an ana$\log$ of geoengineering, Geophys. Res. Lett., 34, L15702, https://doi.org/10.1029/2007GL030524, 2007.

Vecchi, G. A. and Soden, B. J.: Effect of remote sea surface temperature change on tropical cyclone potential intensity, Nature, 450, 1066-1070, https://doi.org/10.1038/nature06423, 2007.

Wang, T., Guo, D., Gao, Y., Wang, H., Zheng, F., Zhu, Y., Miao, J., and Hu, Y.: Modulation of ENSO evolution by strong tropical volcanic eruptions, Clim. Dynam., 51, 2433-2453, https://doi.org/10.1007/s00382-017-4021-2, 2018.

Wilson, R., Cook, E., D’Arrigo, R., Riedwyl, N., Evans, M. N., Tudhope, A., and Rob, A.: Reconstructing ENSO: The influence of method, proxy data, climate forcing and teleconnections, J. Quaternary Sci., 25, 62-78, https://doi.org/10.1002/jqs.1297, 2010 . 
Wittenberg, A. T.: Are historical records sufficient to constrain ENSO simulations?, Geophys. Res. Lett., 32, L12702, https://doi.org/10.1029/2009GL038710, 2009.

Zambri, B. and Robock, A.: Winter warming and summer monsoon reduction after volcanic eruptions in Coupled Model Intercomparison Project 5 (CMIP5) simulations, Geophys. Res. Lett., 43, 10920-10928 https://doi.org/10.1002/2016GL070460, 2016.

Zanchettin, D., Timmreck, C., Graf, H. F., Rubino, A., Lorenz, S., Lohmann, K., Krüger, K., and Jungclaus, J. H.: Bi-decadal variability excited in the coupled ocean-atmosphere system by strong tropical volcanic eruptions, Clim. Dynam., 39, 419-444 https://doi.org/10.1007/s00382-011-1167-1, 2012.
Zuo, M., Man, W., Zhou, T., and Guo, Z.: Different impacts of Northern, tropical, and Southern volcanic eruptions on the tropical pacific SST in the Last Millennium, J. Climate, 31, 67296744, https://doi.org/10.1175/JCLI-D-17-0571.1, 2018. 